Document downloaded from:

http://hdl.handle.net/10251/155437

This paper must be cited as:

Ivars-Baidal, JA.; Celdrán-Bernabeu, MA.; Mazón, JN.; Perles Ivars, A. (2019). Smart destinations and the evolution of ICTs: a new scenario for destination management?. Current Issues in Tourism (Online). 22(13):1581-1600.

https://doi.org/10.1080/13683500.2017.1388771

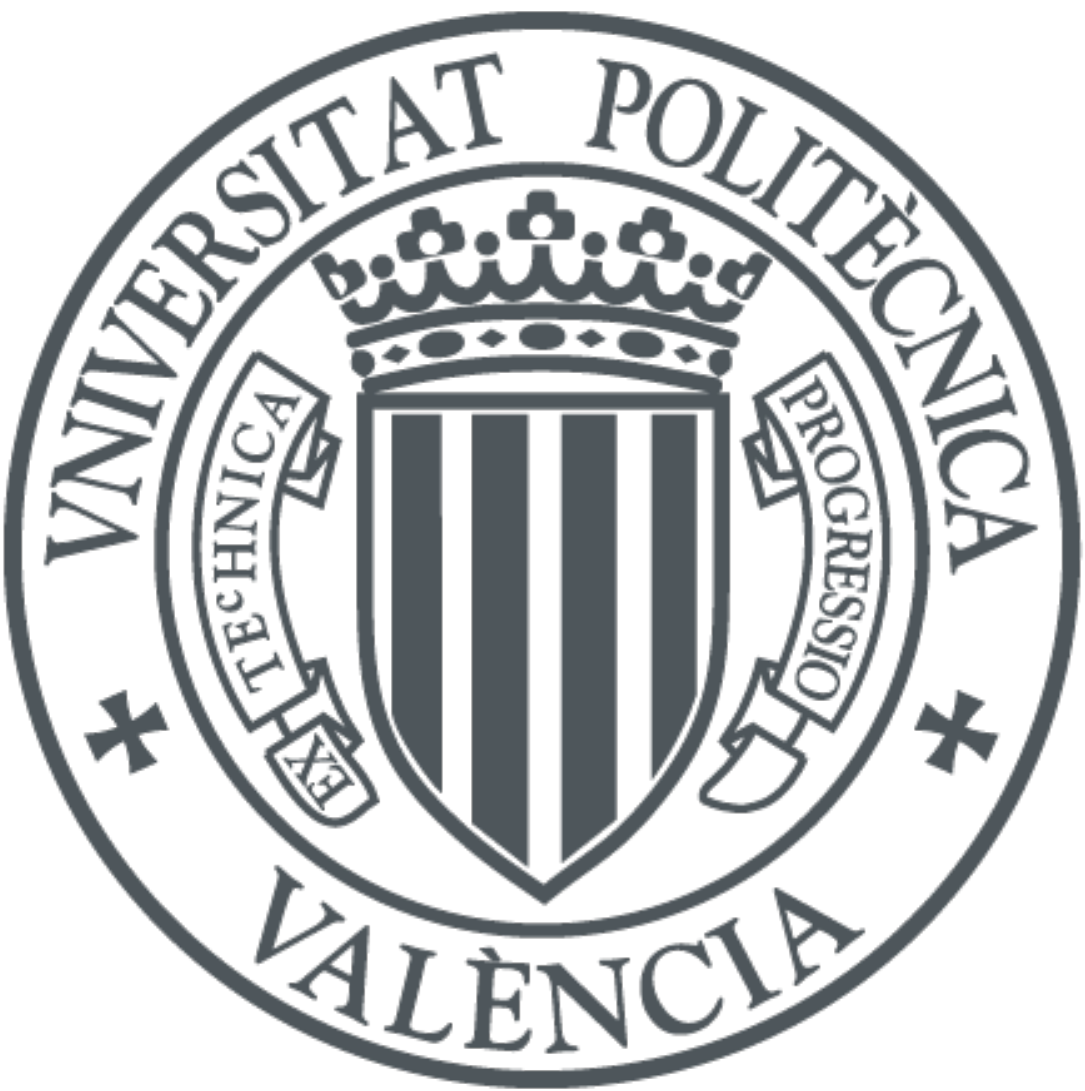

The final publication is available at

https://doi.org/10.1080/13683500.2017.1388771

Copyright Routledge

Additional Information 


\title{
Smart destinations and the evolution of ICTs: a new scenario for destination management?
}

\author{
Josep A. Ivars-Baidala , Marco A. Celdrán-Bernabeu ${ }^{a}$, Jose Norberto-Mazón] and Ángel F. Perles- \\ Ivars $^{\mathrm{b}}$
}

aTourism Research Institute, University of Alicante, Alicante, Spain

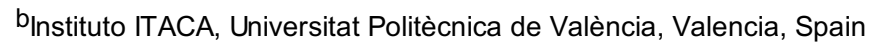

*Corresponding author. Email: josep.ivars@ua.es

The impact of information and communication technologies (ICTs) on tourism and their foreseeable future evolution seem to be shaping a new scenario for destination management. This new context has given rise to the need for new management models. One of these models is the emerging smart tourism destination (STD), although it requires greater conceptual precision in order to become a new paradigm for destination management. This paper proposes a systemic model for STDs which facilitates the interpretation of the role of ICTs in the management of tourism destinations. Accordingly, the Delphi technique has been applied so as to determine the opinion of experts regarding the feasibility of the STD approach, its advantages and limitations and also the size of the impact of ICTs on the management and marketing of tourism destinations. This prospective exercise highlights the intensification of the impact of ICTs over the coming years which will shape a new scenario for management characterised by technology and data management. However, the efficiency of the STD approach will not depend exclusively only on technology but also on an appropriate governance of the destination that systematically incorporates the three levels of the STD, namely the strategic-relational, instrumental and applied levels.

Keywords: smart tourism destinations; ICTs; destination management organisations; technology forecasting

\section{Introduction}

Information and communication technologies (ICTs) constitute a basic pillar of the digital economy. Their evolution has created a favourable environment for new management approaches for cities. The universalisation of the Internet has given rise to the emergence of different proposals: the Intelligent, Smart, Digital, Wired, Cybercit] or Knowledge city (Komninos, 2002); of these terms, "smart" has prevailed. The common denominator of these concepts resides in the description of cities with knowledge centres that manage information, technology and innovation; aspects that favour more efficient management, sustainable development and a better quality of life for citizens (Caragliu, \& Del Bo,\&,Nijkampo, 2012; Giffinger etal., 2007). A smart city is defined as "an urban imaginary combining the concept of green cities with technological futurism and giving a name to technocentric visions of the city of tomorrow" (Vanolo, 2014, p.894). This prominent technological relationship has generated criticism of this new imaginary as it benefits the large technological companies, favours the privatisation of public services and technological dependency, generates uncertainty regarding the privacy of citizens or is used as a mechanism that serves to depoliticise urban management, when the concept of the smart city is far from apolitical and non-ideological (Greenfield, 2013; Kitchin, 2015; March \& Ribera-Fumaz, 2016; Townsend, 2013; Vanolo, 2014).

Since its inception in the urban environment, the smart approach has been subsequently applied to tourism destination management, and the term smart tourism destination (STD) has been coined. This approach seems particularly relevant in a sector where the frenetic evolution of ICTs constitutes one of the most relevant factors for change (Law, Buhalis, \& Cobanoglu, 2014). The influence of ICTs is not new in the highly information-intensive activity of tourism, and their importance has been apparent since central reservation systems evolved into global distribution systems (Sheldon, 1997). However, the consolidation of the Internet at the end of the 1990s marked the beginning of the digital revolution in the tourism industry, extended by the growing use of mobile devices and social media (Benckendorff, Sheldon, \& Fesenmaier, 2014; Buhalis, 2003; Buhalis \& Law, 2008; Cetin, Aydogan Cifci, Istanbullu Dincer, \& Fuchs, 2016; Sigala, Christou, \& Gretzel, 2012; Xiang, Tussyadiah, \& Buhalis, 2015). The rapid adoption of ICTs by tourism demand has transformed the management and marketing of tourism (Gretzel, Yuan, \& Fesenmaier, 2000), and these tools have become a basic factor of competitiveness for tourism destinations (Buhalis \& Matloka, 2013).

As a result, combining the STD approach with the use of ICTs seems to have given rise to the emergence of a new scenario for tourism destination management. This article seeks to analyse the extent to which a new scenario is taking shape for managing destinations and examines the new features that define it. First, it will address the STD concept within the context of the new conceptual approaches to tourism destinations, with special emphasis on the role played by technology. Subsequently, through the use of the Delphi technique, the opinion of experts in the concept of smart destinations and their feasibility will be analysed. Furthermore, a prospective exercise aimed at determining the impact of the evolution of ICTs on tourism and their repercussions on tourism destination management will be conducted. This will enable us to identify the fundamental elements that would shape the new scenario for destination management based on STDs, their potentialities and limitations.

Therefore, the overall objective of the paper is to contribute to defining the new scenario for destination management shaped by the STD and the evolution of the ICTs, their potential for development and their drawbacks. This general aim comprises two specific objectives: to analyse the STD as a future paradigm for the management of tourism destinations and to assess the size of the impact that ICTs have on tourism management and their connection with the STD approach. 
The complexity of tourism destinations, due to their many components and their internal interrelations on a local scale and external interrelations on a global scale, is reflected in the new conceptual approaches and their attempts to systematise different theories (Jovicic, 2016; Pearce, 2014; Saraniemi \& Kylanen, 2011). In an interesting summary of the conceptual foundations of destinations, Pearce points out that the way "we conceptualize and frame destinations is critical not only for the research that we do but also for practical matters such as destination management and marketing" (2014, p.141). In his study, Pearce identifies five sets of concepts (industrial districts, clusters, networks, systems and social constructs) according to three major dimensions (geographic, mode of production and dynamic), in order to propose an integrative conceptual framework of destinations. This systematisation incorporates elements that are central to the STD concept, such as innovation or knowledge, but only minor references are made to ICTs.

The direct link between ICTs and destination management was first made during the development of the first destination management systems (DMS) in the 1980s (Benckendorff etal., 2014). In the 1990s, Poon (1993) highlighted the growing and decisive importance of technology in the competitive strategy of destinations, but it was the Internet and web-based systems that generated a quantitative and qualitative boost in the use of ICTs for destination management. The digitalisation of the tourism value chain gave rise to e-Tourism from which the e-Destination concept was derived and the evolution of the DMS towards Destination Integrated Computerised Information Reservation Management Systems played a fundamental role as a strategic tool for destination operational and strategic management (Buhalis, 2003).

The role of ICTs in tourism management can also be explained from the perspective of the digital ecosystems. Benckendorff etal. (2014) consider that a digital tourism ecosystem is composed of the interactions between living entities such as travellers or suppliers and the non-living technological environment of devices, connections, etc., and that the concept could be applied to a specific destination, to a particular sector of the travel industry or to the global travel phenomenon. Del Chiappa and Baggio (2015) define a tourism destination, combining the digital business ecosystem and network theories, as a networked system of stakeholders delivering services to tourists, complemented by a technological infrastructure aimed at creating a digital environment which supports cooperation, knowledge sharing and open innovation.

The differentiating feature of the proposals for conceptualising STDs is the role played by technology. Buhalis and Amaranggana (2014) identify the need for a technological platform that dynamically interconnects the different stakeholders, enables the instant exchange of information and can be accessed by a variety of end-user devices, facilitating the creation of real-time tourism experiences and improving the efficiency of tourism resource management.

For Gretzel, Sigala, Xiang, and Koo (2015), smart tourism constitutes a distinct step forward in the evolution of ICTs in tourism and is made up of three main layers (smart destinations, smart business ecosystems and smart experience). These authors maintain that the key aspect of smart tourism is the integration of ICTs into physical infrastructures. Using this approach, it is clear that there is a complex relationship between the destination and the ecosystem, given that the term "destination" practically refers to a tourism-based ecosystem, which overlaps with other ecosystems (such as the residential one), and is made up of companies that operate on different scales (franchised companies, international distribution chains, etc.) and, of course, in connection with the tourism source markets (Gretzel, Werthner, Koo, \& Lamsfus, 2015). Following this reasoning, it is not simple, or advisable, to isolate the STD inside the global tourism-based ecosystem. It is better to identify the key elements of its integration in the tourism ecosystem, which is a fundamental aspect of a destination's level of smartness.

Furthermore, applying ICTs to destination management is common. Therefore, in the conceptual debate on STDs, it is important to identify which technologies make a destination smart. Gretzel, Sigala, etal. (2015) consider that smart tourism is a direct extension of e-Tourism and can be distinguished through the connection of the physical with the digital, thanks mainly to the development of the Internet of things. E-Tourism, on the other hand, is focused on Internet-based business-consumer and consumer-consumer connections which facilitate electronic transactions. Bearing these considerations in mind, smart tourism is defined by the joint efforts in the destination to obtain information from physical and digital sources which, combined with advanced technologies, are capable of transforming the data into experiences and business value propositions focused on efficiency, sustainability and experience enrichment (Gretzel, Sigala, etal., 2015).

The reference to advanced technologies introduces another perspective in the analysis: to what extent do STDs use smart technologies? Gretzel, Werthner, etal. (2015) refer to the six aspects or levels of smartness for technology proposed by W.Derzko which include adapting to the environment, learning capacity, anticipation and self-organisation. However, the STDs incorporate a large number of technologies, combining the more advanced types, such as artificial intelligence, with more conventional technologies, such as mobile applications.

The theoretical debate coexists with policies for developing smart tourist destinations. In Asia, China and South Korea, policies are oriented towards creating a technological infrastructure to develop smart tourism, utilising the opportunities of the ICTs for the marketing and management of the destinations and tourism resources (Gretzel, Sigala, etal., 2015; Guo, Liu, \& Chai, 2014; Koo, Shin, Gretzel, Canon, \& Chung, 2016; Li, Hu, Huang, \& Duan, 2017; Wang, Li, \& Li, 2013). In Europe, the initiatives are related to the innovation and competitiveness of the destinations through the development of smart end-user applications which are associated with smart city strategies, specific tourist programmes (Segittur, 2015) or, in cases such as Italy, programmes that link culture and tourism (Graziano, 201]). Finally, in Australia, policies focus mainly on smart governance and the use of open data (Gretzel, Sigala, etal., 2015).

Logically, the support provided by institutions for the development of smart destinations is mostly related to management and is very similar to the smart city strategies. The global concept of the smart city has led to more ambitious approaches which are free from rhetoric and political-institutional propaganda. The holistic approach covering the different spheres of the smart city proposed by Giffinger etal., 2007 (smart economy, people, mobility, environment, living and governance) has been applied mutatis mutandis to the STD. The STD programme developed in Spain by SEGITTUR (Tourism Innovation and Technologies state-owned company), defines the STD as a tourism destination that is innovative, sustainable and accessible to everyone which is based on an infrastructure of state-of-the-art technology that increases the quality of the experience at the destination and improves the quality of life of residents (SEGITTUR, 2015). This is a practically perfect idea of a tourism destination. However, the difficulty resides in making it a reality. For this reason, operative STD models are necessary in order to provide bridges between scientific knowledge and destination management. According to Boes, Buhalis, and Inversini (2015), a holistic perspective is necessary to take full advantage of ICT infrastructures and technological applications in the STDs.

The STD models contributing to this holistic and applied perspective include the model proposed by Ivars, Solsona, and Giner (2016), which acknowledges the enabling role of ICTs in shaping an STD based on strategic and relational prior conditions that determine a destination's capacity for action and the scope of its STD strategy. The model is structured into three interrelated levels (Figure 1): the strategic-relational level, based on a governance characterised by public-private cooperation in order to guarantee the sustainability of the destination and an open and collaborative environment of innovation; the instrumental level, based on digital connectivity and sensoring so as to configure a destination information system that is essential for decisionmaking; the applied level, which enables the development of smart solutions for the marketing and management of the destination, giving rise to greater efficiency in communication actions and an improvement in the tourism experience. 
Figure 1. Systemic STD model. Own elaboration based on Ivars etal. (2016).

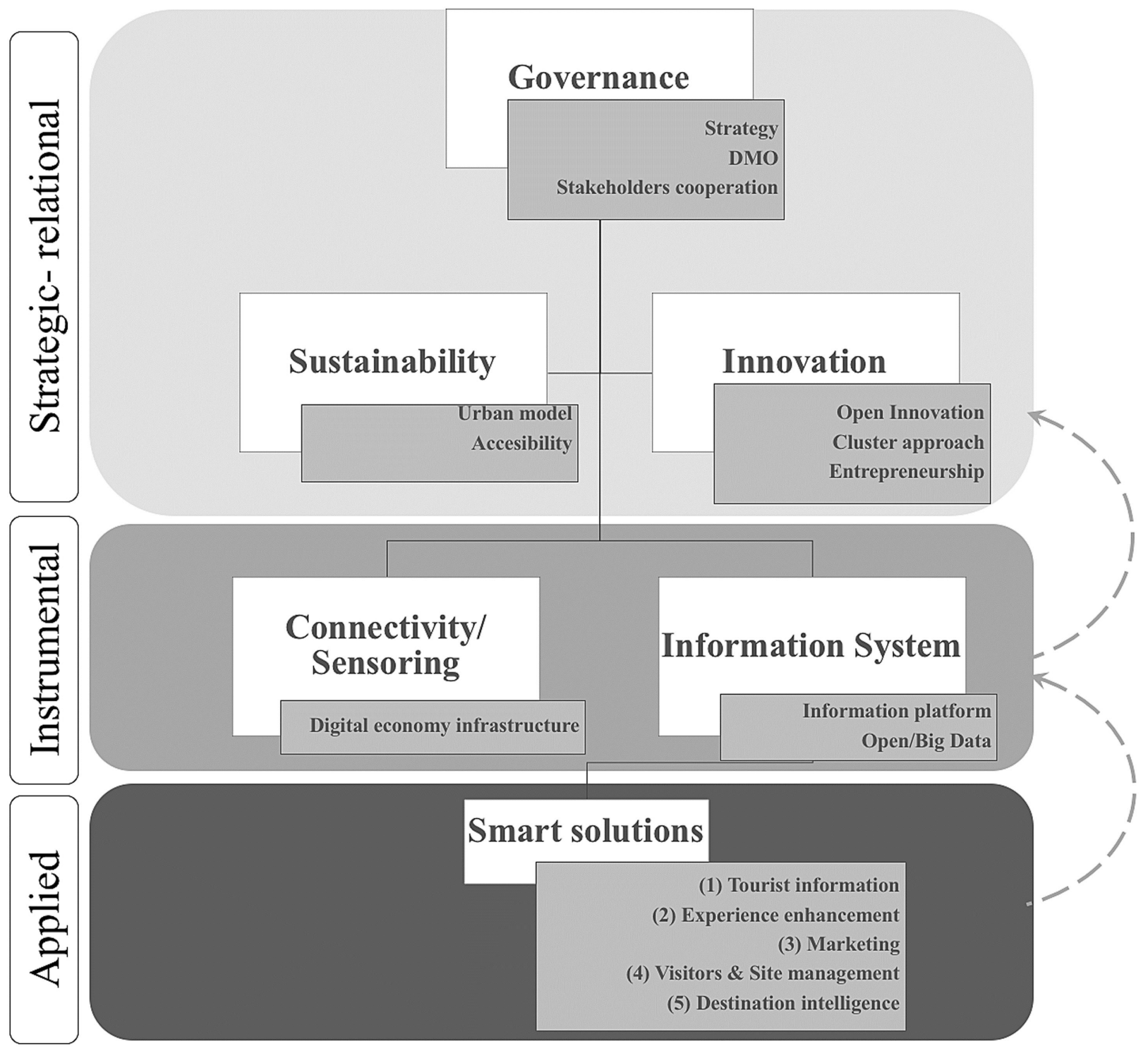

For an optimum development of the instrumental role played by ICTs, it is essential to identify the management needs and capacity of the tourism destination. The STD strategy should respond to the local context and to the characteristics of how each destination integrates into the global tourism ecosystem. However, it is also possible to identify, in general terms, the technology-based solutions related to the STDs that represent substantial improvements in the following fields of tourism management:

1. Tourist information. Ubiquitous information anytime, anywhere and in any device, with the possibility of influencing the whole tourist travel cycle (dreaming, planning, booking, experiencing and sharing in accordance with Google's five stages of travel; Google, 2014) and creating a new relationship framework between the tourist and the destination through user-generated content and a continuous interaction between the two, based mainly on the use of social networks (Chung \& Koo, 2015; Munar \& Jacobsen, 2014; Sigala etal., 2012).

2. Experience enhancement. Experiences in the destination could be improved through the application of different technologies that facilitate tourism consumption (local connectivity, mobile payments, biometric solutions, etc.), enrich the tourism experience (virtual and augmented reality, ambient intelligence, etc.) (Tussyadiah, Wang, \& Jia, 2017) and increase the possibilities of the co-creationand personalisation of tourist services (Buhalis \& Amaranggana, 2015; Neuhofer, Buhalis, \& Ladkin, 2012).

3. Marketing. Increased possibilities of marketing the tourism destination. The information available in real time enables considerable advances to be made towards a more personalised marketing (Niininen, March, \& Buhalis, 200]) and a greater development of location-based marketing (Berger, Lehmann, \& Lehner, 2003) with new proximity marketing, instant marketing or cross-selling approaches. This framework of context marketing encompasses the SOCOMO (social context mobile) model defined by Buhalis and Foerste (2015). Similarly, the use of smart solutions may increase the transactional role of the Destination Management Organisation (DMO) through, for example, the increase in reservations made through the official website, facilitating the online reputation management of the destination or adapting traditional tools so that they can provide smart solutions, as in the case of the smart cards analysed by Angeloni (2016).

4. Visitors \& Site management. More efficient management of visitors through the application of a sensor network that enables the development of the Internet of Things (Wang etal., 2013), particularly appropriate for fragile spaces (such as smart heritage applications for historical buildings that measure the degree of conservation and the impact of the visits) or for crowded areas. The contribution of this approach is twofold: it ensures both the quality of the visitor's experience and the sustainable management of the tourist space or attraction. This perspective opens the possibility of analysing the degree of smartness of tourist attractions (Wang, Li, Zhen, \& Zhang, 2016).

5. Destination intelligence. Greater knowledge of the demand and the management variables of the tourism destination. The use of the destination's website, social networks or mobile applications and other technologies provides the tourist with 
information and the tourism destinations with a large amount of data that can be crossed with other variables related to the tourist experience, such as weather, environmental or traffic information. Therefore, a new horizon for DMS has been created in which open data (Pesonen \& Lampi, 2016) and the application of big data analysis techniques (Baggio \& Scaglione, 2017; Fuchs, Höpken, \& Lexhagen, 2014; Marine-Roig \& Anton Clavé, 2015) are particularly interesting. Smart systems incorporate different technologies (recommender and context-aware systems or deep learning, among others) which transform them into essential instruments for supporting decision-making and the design of new tourist experiences (Gretzel, 2011; Gretzel, Sigala, etal., 2015). The application of smart solutions fosters innovation, entrepreneurship and knowledge-based tourism management. The development of these solutions favours cooperation and the exchange of information between the stakeholders and promotes a type of knowledge-based management linked to the learning destination concept (Cooper \& Sheldon, 2010; Fuchs etal., 2014; Schianetz, Kavanagh, \& Lockington, 2007) or the innovation-based learning economy (Hall \& Williams, 2008).

This systemic approach highlights how smart solutions provide feedback on the basic aspects of the strategic-relational level (for example, innovation or the collaboration between stakeholders) and of the instrumental level (increase in the data available for the destination's information systems). In this way, the development of the STD generates synergies that give rise to continuous improvement and the creation of a process capable of transforming tourism destination management.

Therefore, it seems that a new scenario is emerging for the management of tourism destinations, creating the need to assess the feasibility of the STD approach and measure the impact of the technological evolution in order to identify its current and future influence on destination management.

\section{Methodology}

This study conducts an in-depth analysis of the STD approach from a theoretical and applied perspective. First, the STD was conceptualised and the ICTs that enable the development of smart solutions were identified. Subsequently, the Delphi technique was used to obtain the opinion of experts regarding the feasibility of the STD approach, its advantages and limitations and their predictions regarding the size of the impact of the ICTs related to the STDs and the period in which this impact will reach its maximum level.

The assessments from the experts were obtained through Internet-based Delphi research. This is a technique which was developed by RAND Corporation in the 1950s and has evolved into a widely used tool in both academic and professional fields (Donohoe \& Needham, 2009). Its main goal is to obtain a reliable consensus of a panel of experts with a high level of knowledge of the subject under analysis (Okoli \& Pawlowski, 2004). It is a method well-suited for analysing complex problems (Donohoe \& Needham, 2009) and forecasting uncertain factors (Cole, Donohoe, \& Stellefson, 2013), such as the impact of the evolution of ICTs on tourism. In fact, Kanama, Kondo, and Yokoo (2008) defend the considerable potential of integrating the Delphi method in technology roadmapping. However, the Delphi method is not exempt from criticism: it is sensitive to design characteristics (panel expertise and composition, question clarity, outlier management and reporting, questionnaire administration), it is vulnerable to high attrition rates, it uses subjective information, the interaction between the experts is limited, the anonymity of the test frees the participants from responsibility, it generates "deceptive consensus" or it is difficult to guarantee the participation of experts with sufficient interest and dedication (Cole etal., 2013; Donohoe \& Needham, 2009; Garrod \& Fyall, 2000, 2004; Landeta, Barrutia, \& Lertxundi, 2011).

The Delphi method was developed and applied in three main stages: (1) the design and testing of the questionnaire, (2) the selection of the experts and the sending of the first and second round questionnaires and (3) the analysis of the results. Different versions of the questionnaire were created and a pre-test analysis was performed to ensure its feasibility. The identification of the technologies was especially important, together with the inclusion of a glossary of terms in the questionnaire to facilitate understanding of the technologies and to avoid individual interpretations not shared by all the participants (see Appendix 2). Furthermore, the experts had the opportunity to complement and refine their responses to each of the questions, which provided qualitative information that is interesting for the interpretation of the results.

The review of the scientific literature on ICTs and tourism and the analyses and reports of technological and/or tourism consulting firms, such as Gartner or Phocuswright, enabled the ICTs that are related to STDs to be identified. This generated an extensive inventory which had to be refined through an analysis conducted by tourism and ICT experts in order to select the list of technologies that would be included in the Delphi questionnaire.

The selection of the experts was based on the analysis of their scientific production related to ICTs and tourism and on a review of international events in this field in which specialists from tourism companies and organisations have participated and who have sufficient expertise to take part in this research.

The experts selected were all academics, specialised in tourism and ICTs. They have published in international journals, participated in international congresses on this subject or are professionals with ICT skills working in global tourism companies. With these criteria, 45 potential participants were initially selected. A large number of experts were identified with the idea of obtaining a minimum of 20 responses. The first online questionnaire that was sent received 24 responses, which were considered as being sufficient. In the second round, two questionnaires were not returned so the number of final valid participants was 22 experts. Most of the final group of experts were academics (16), working in universities, although many of them collaborated with tourism companies and destinations. The professionals were mainly consultants specialised in technology and tourism. The geographical distribution is highly varied, an advantage of the e-Delphi method, since eight experts develop their activity in Spain, five in the United Kingdom, two in Australia and one each in Portugal, India, Finland, Poland, the United States, Brazil and Italy.

Qualtrics $\odot$ software was used for sending and monitoring the questionnaire, analysing the results of the first round, systematising them for the second round, and calculating the mean, median and standard deviation compared with each individual response. The first and second rounds of the questionnaires were sent out between October 2015 and June 2016. Without a doubt, obtaining a consensus is one of the most interesting and controversial aspects of the Delphi method. It is also one of the most costly in terms of the dedication of the experts during the different response rounds. In this study, the two rounds were considered sufficient to achieve the proposed objectives. The results reveal a high level of consensus in the assessment of the STD approach and a lesser degree of consensus in the forecast impact of technologies, and an even lower degree of consensus with respect to the time period when the ICTs will reach their maximum level of impact. In order to assess whether a third round of questionnaires was appropriate, the change in the coefficient of variation (CV) (the division of the standard deviation with the mean) was measured for each item between the two rounds. The CV is a statistical measure of the dispersion of data which is particularly appropriate when levels of variability in data need to be compared. An absolute CV difference of close to zero for each item in the Delphi survey indicates a substantial stability of responses and could be considered as a stopping rule(Landeta, 1999). In this sense, the difference between the CV of the second round and that of the first was higher than 0.10 in only $2.4 \%$ of the questionnaire items. Therefore, it was decided that a third round would not be carried out. 
The exploitation of the results obtained from the Delphi method has been structured into two sections: the first refers to the smart destination concept, the advantages to be gained, the extent to which the smart solutions are relevant and also the barriers to applying this approach. The second section refers to the forecasted impact of the destination management technologies. In the first section, focused on the assessment of the STD approach, the degree of consensus reached is higher, whereas the responses are more disperse in the section.

\section{STD concept and viability}

The opinions of the experts reflect the need to engage in a theoretical debate that is not exempt from controversy. If we aggregate the responses that agree with the proposed issues (I agree and I strongly agree), on the one hand, the majority of the participants $(86 \%)$ are unwilling to consider the smart destination concept as a passing trend, although a high percentage $(70 \%)$ consider it to be a rhetorical and imprecise concept. The interest of the smart focus is evident in the high level of agreement regarding its validity for integrating ICTs in the management of destinations $(91 \%)$, its capacity to transform the destinations $(91 \%)$ and to incorporate added value into their management (95\%). However, in line with the assessments regarding technological evolution, $68 \%$ of the experts consider that this focus is still experimental and a greater maturity of the technologies is required. Furthermore, $64 \%$ indicate that an international standard should be created that accredits the STDs. This initiative is in the development phase in Spain as the Standard 178,501 for the application of a smart DMS has been approved in 2016 by the Agencia Española para la Normalización (Spanish Standardisation Agency) (AENOR).

The main advantages of the STD approach are the increase in the competitiveness of the destination, the enhancement of the satisfaction of the demand and the development of new products. Furthermore, it contributes to increasing tourist spending and public-private collaboration. Finally, less relevant advantages include the increase in demand and the emergence of new sources of finance in the destinations. Therefore, it is assumed that the STD approach improves the efficiency of tourism management and increases the competitiveness of the destination but does not necessarily lead to an increase in the number of tourists (Figure 2).

Figure 2. Benefits of applying the STD approach (aggregated \% answering I agree and I strongly agree).

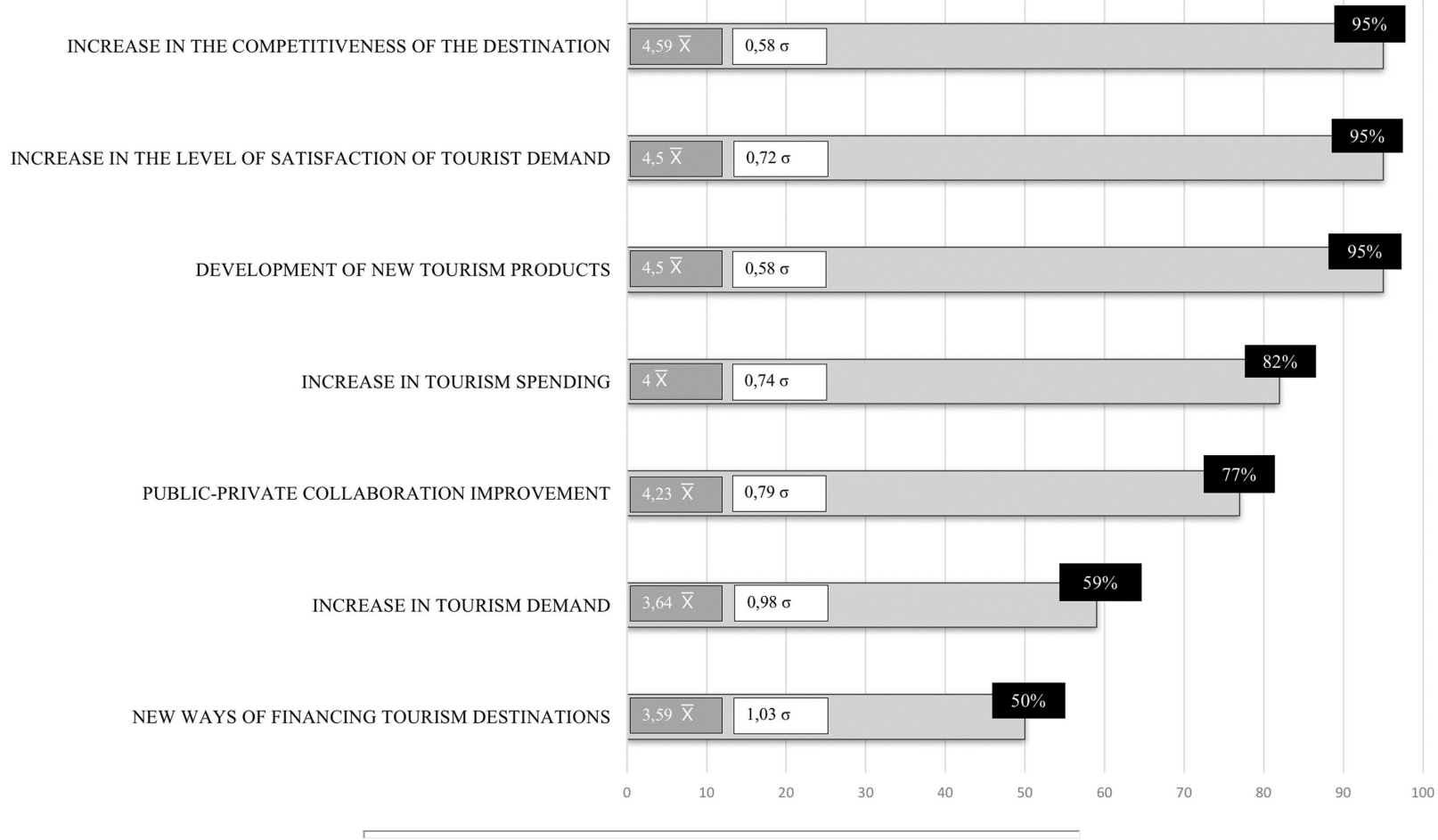

In keeping with the advantages identified, the most relevant solutions focus on key aspects of tourism destination management with very high percentages of agreement. Only the new possibilities of distribution supply and governance are below $90 \%$. On the other hand, the impact of the STD on collaborative consumption and the interaction between tourists and residents is perceived as being less relevant (Figure 3).

Figure 3. Degree of relevance of the smart solutions for destination management (aggregated $\%$ answering relevant and very relevant). 
PROMOTION OF COLLECTIVE INTELLIGENCE AND KNOWLEDGE AT DESTINATION

IMPROVEMENT IN MANAGEMENT OF RESOURCES / TOURIST ATTRACTIONS

GREATER SUSTAINABILITY

INCREASED INNOVATION

TRAVEL EXPERIENCE ENHANCEMENT

DEVELOPMENT OF NEW BUSINESS MODELS

NEW POSSIBILITIES FOR ONLINE MARKETING

BETTER CUSTOMIZATION OF THE TOURIST-DESTINATION RELATIONSHIP

NEW DISTRIBUTION SUPPLY POSSIBILITIES

GOVERNANCE IMPROVEMENT

INCREASE IN COLLABORATIVE CONSUMPTION

MAJOR TOURIST-RESIDENT INTERACTION
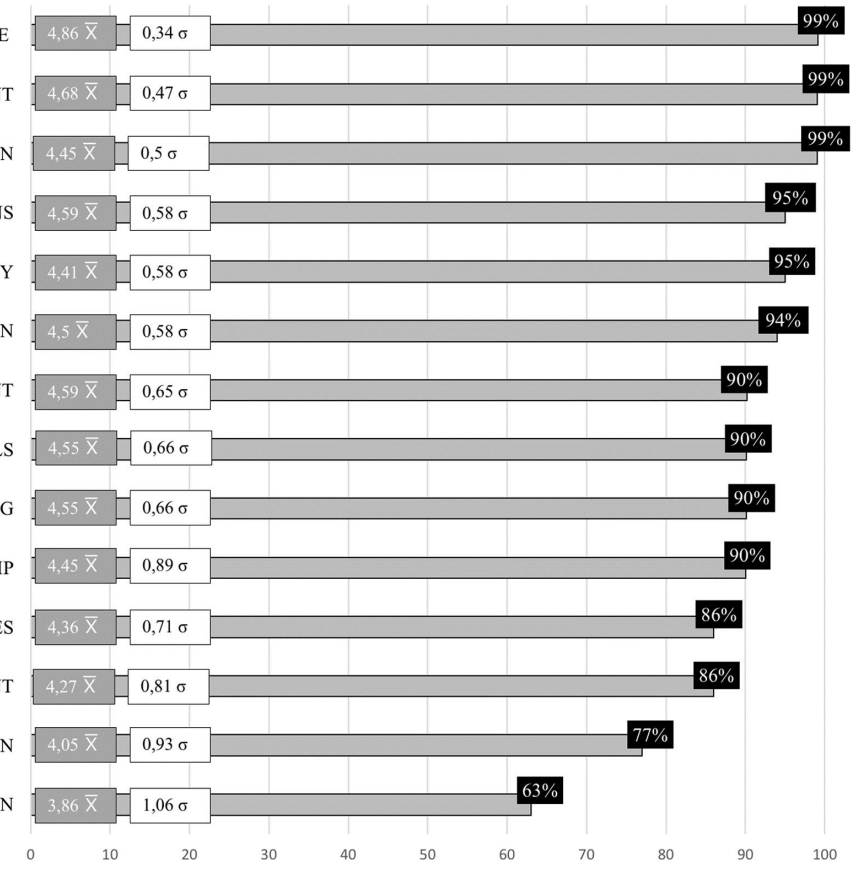

$\left.\right|_{90}$

With respect to the barriers that hinder the application of the STD approach, the opinion of the experts reveals the need to rethink tourist destination management so as to redress the lack of a strategy and the failure to adapt to change, the political short termism, the lack of coordination between different departments and the deficit of economic resources. From the technological point of view, the insufficient interoperability of the systems is considered to be a fundamental barrier. A second group of barriers, with a medium level of importance, are related to the insufficient public-private cooperation and the structural characteristics of the tourism sector: low capacity to absorb innovation, lack of ICT know-how, predominance of small- and medium-sized firms, limitations of competences to act with respect to all of the elements that define the STD or the insufficient collaboration between companies and research centres. However, legislation is not seen as a barrier and it is clear that tourist engagement, far from being a hindrance, constitutes one of the basic drivers of the development of STDs (Figure 4).

Figure 4. Degree of importance of barriers in applying ICTs to tourism destinations (aggregated \% answering important and very important).

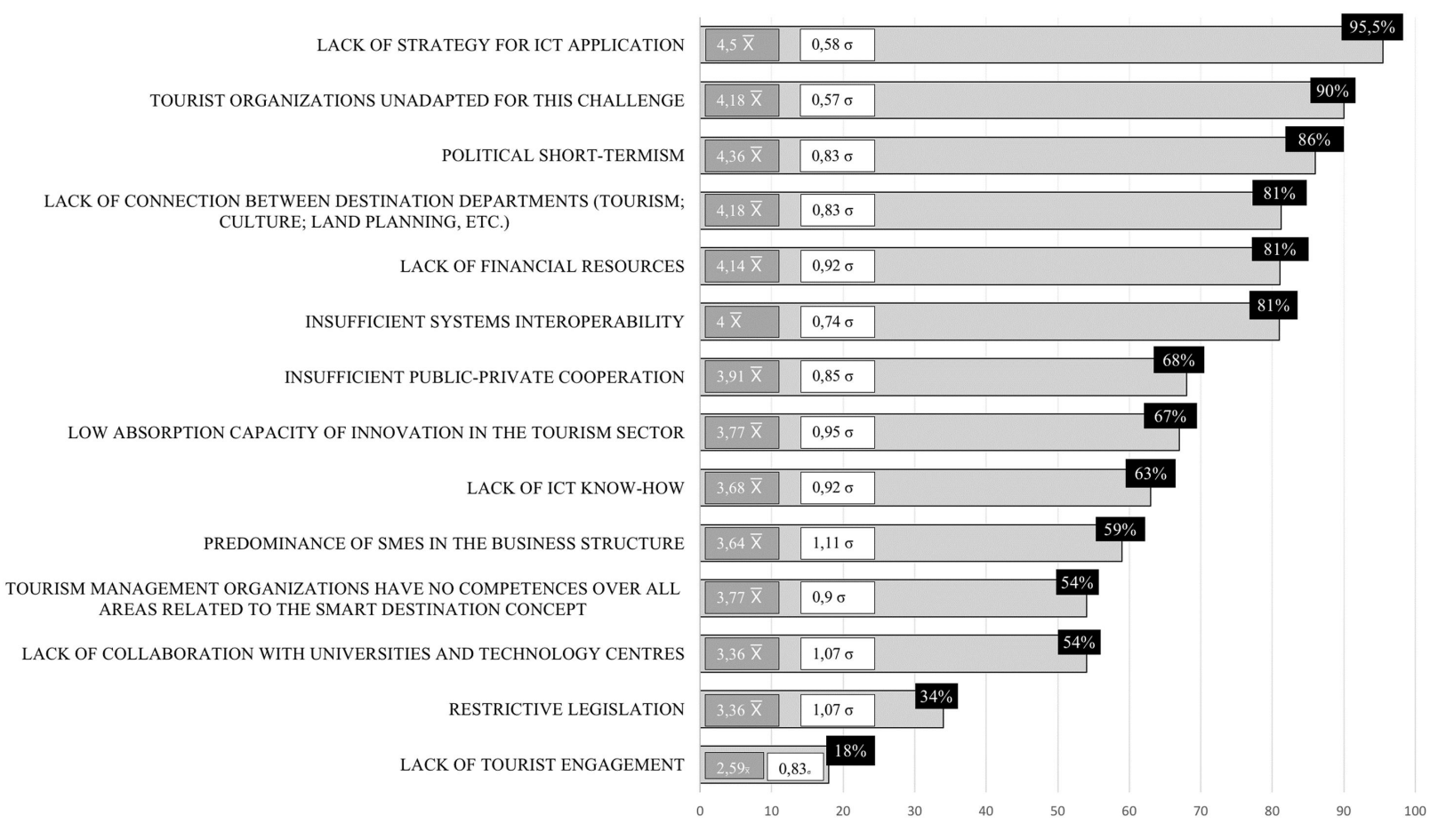

From a qualitative point of view, the contributions of the experts indicate a need to avoid a technological bias so as to incorporate the principles of governance mentioned above and the need for a global focus that goes beyond the marketing of destinations to incorporate sustainability and the quality of life of the local population. In particular, it is considered that technology can help to establish a better balance between the satisfaction of tourists and the quality of life of the residents.

From a more critical perspective, reference is made to the need to analyse who controls the technology, its objective and who benefits from the smart destination projects. Furthermore, despite an acknowledgement that certain organisations in a tourism 
destination are interested in smart solutions, their integrated application, which benefits the many stakeholders of the destination, is considered impractical. Therefore, difficulties arise from the lack of involvement of the stakeholders and there are doubts withrespect to how secure the digital information shared between the agents of the destination is.

\section{Prospective of ICTs: implications for smart destination development}

In view of the avalanche of technologies related to STDs, it is advisable to identify those that have the greatest impact on destination management and, wherever possible, to estimate when their highest level of impact will occur. Despite its limitations, the Delphi technique is suitable for this objective. The experts have given their opinion about technologies aimed at the management and marketing of tourism destinations, which is their field of work or research. Other areas of the STD approach, such as sustainability, have not been included in the analysis due to the difficulty in addressing a greater number of complex technologies for which a different kind of expert is required (energy efficiency, smart metering, urban mobility, waste treatment, etc.). Even so, the difficulties involved in this prospective exercise are clear. Geels (2002) describes tourism as an activity that functions through the interplay of multiple technologies, which are parallel and even equally important. According to Kelly (2016), technologies are co-dependent within a process of technological, socio-economic and institutional co-evolution. Furthermore, nearly every field of science and technology contains some foundations for the future of tourism and much of the innovative power in this industry does not originate from tourism itself (Hjalager, 2015). Innovation in tourism is fostered by external driving forces including the external suppliers of technology (Jolly \& Dimanche, 2009), which, in the case of the smart cities and STDs, exhibit a large capacity to influence urban and tourism management (Komninos, 2015).

From a theoretical point of view, Benckendorff etal. (2014) identify three theories that explain the social adoption of new technological innovations in an economy: the diffusion of innovations theory (Rogers, 1962), the technological innovation theory (Perez, 2002) and the Gartner Hype Cycle. The cycle proposed by Gartner presents the challenge of choosing the right innovation, in this case the right technology, at the right time (Fenn \& Raskino, 2008). Five stages are considered: the innovation trigger, the peak of inflated expectations, the trough of disillusionment, the slope of enlightenment and the plateau of productivity. This cycle appears to be particularly appropriate for analysing the evolution towards smart destinations, according to which the current concept of smart destination can be considered as an innovation at the peak of inflated expectations that has yet to be more widely implemented (plateau of productivity). Many other technologies, however, while having a considerable media impact, are not yet really applicable to the management of destinations. This explains why it is interesting to obtain the opinion of experts with which to generate a roadmap that will serve as a reference for the management of destinations in the present and the immediate future.

The maximum level of impact and use of ICTs in tourism is more complex to estimate. This is clear in a lower consensus in the answers given by the experts. It is evident that the origin of the generalisation of their use, which would equate to the "plateau of productivity" of Gartner Inc. (Fenn \& Raskino, 2008), is multicausal and difficult to assess. In this respect, the experts have made interesting qualitative comments in which they highlight that the life cycle of the technology is not linear, as proposed for innovation in tourism: "Why do some innovations affect tourism rapidly and substantially, while others stagger for a long time before they are exploited in a tourism context?" (Hjalager, 2015, p. 19). Furthermore, the technologies may be available but the managers of the destinations may not apply them owing to lack of knowledge, lack of technical ability or insufficient investment capacity, among other factors, not forgetting the possibility of radical changes in the technology that may alter the initial forecasts.

The analysed technologies have been divided into six groups, according to the review of scientific literature on ICTs and tourism: connectivity; wearables; identity, payments and security; sensorial experiences; other technologies; and data management. The experts were asked to give their opinion regarding, first, the degree of the impact of the selected technologies on tourism (low, medium, high) and, second, their forecast regarding the period of maximum impact/use in the tourism sector (today; short, medium and long term; and uncertain). The results can be seen in Figure 5. The technologies with a degree and period of impact that exceed $51 \%$ of the answers are shown in bold. The rest of the technologies are located in the matrix in the position derived from the majority opinion. Furthermore, in parentheses it is indicated whether the responses have not reached $51 \%$ of the total with respect to impact (I), to the time period of this impact $(T)$ or in both cases, a circumstance which reflects a lesser degree of consensus (I-T). Tables with the responses expressed as percentages can be found in the Appendix 1.

Figure 5. ICTs and Tourism Forecast Matrix: Degree of impact and period of maximum use. 


\begin{tabular}{|c|c|c|c|}
\hline \multirow{4}{*}{ 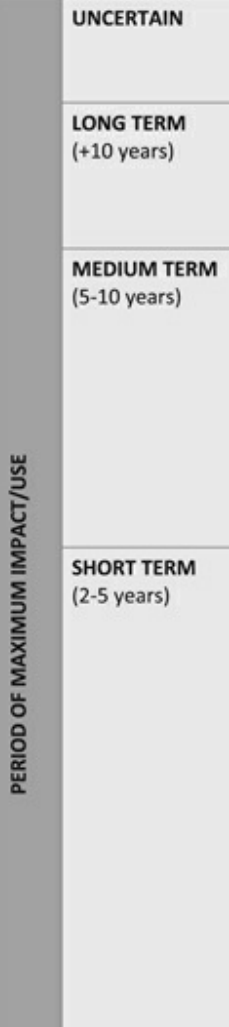 } & Cryptocurrencies (I-T) & & \\
\hline & & & Autonomous Vehicles \\
\hline & & $\begin{array}{l}\text { Ambient Intelligence } \\
\text { Fi-Ware (I-T) } \\
\text { Wearable G. Glass \& the like (T) } \\
\text { Other wearables (T) } \\
\text { Volumetric and Holografic displays (I-T) } \\
\text { Gesture Control (I) } \\
\text { Complex Events Processing (I-T) } \\
\text { 3D Printing (T) }\end{array}$ & $\begin{array}{l}\text { Robots } \\
\text { Enterprise Service Bus } \\
\text { Open Data(T) } \\
\text { Deep Learning (I-T) }\end{array}$ \\
\hline & & $\begin{array}{l}\text { Wearable smartwatch } \\
\text { Fingerprint Biometrics (I-T) } \\
\text { Digital Security (I-T) } \\
\text { Mashups (T) } \\
\text { Question answering (T) } \\
\text { Graph database (I-T) } \\
\text { Document Oriented Database (T) }\end{array}$ & $\begin{array}{l}\text { Real-time Databases } \\
\text { Local Connectivity (Wi-Fi, ...) } \\
\text { Mobile Connection Payments } \\
\text { 5G } \\
\text { Bluetooh low energy (4.0) } \\
\text { NFC Payments } \\
\text { Wearables (cards, etc.) } \\
\text { Augmented reality } \\
\text { UAVs } \\
\text { loT (T) } \\
\text { Big Data (T) } \\
\text { Tourism Intelligence Platform (T) } \\
\text { Semantic Web (T) } \\
\text { Virtual reality (I-T) } \\
\text { Internet IPv6z (T) } \\
\text { Portable Wi-Fi(T) } \\
\text { Text mining (T) }\end{array}$ \\
\hline \multirow[t]{3}{*}{ TODAY } & QR Codes (I) & & $\begin{array}{l}\text { Opinion mining } \\
\text { Web mining (T) } \\
\text { Recommendations system (T) }\end{array}$ \\
\hline & Low & MEDIUM & HIGH \\
\hline & \multicolumn{3}{|c|}{ IMPACT ON TOURISM } \\
\hline
\end{tabular}

The results reveal that the maximum impact of the emerging technologies will take place in the short term (2-5 years). This circumstance enables us to infer that the true development of STDs will occur in this period. It is probable that the effects of the rapid technological evolution in tourism will intensify over the next 2-5 years, or that, at least, technologies with a low level of application, even experimental, may become widespread in tourism in the next 5 years. Currently, there are three technologies related to data management (opinion and web mining and recommendations system) which are considered to already have a high impact on tourism management while the effect of the QR codes is considered to be lower. The technologies with a high impact and reach a higher level of consensus among the experts (over $70 \%$ ), are, in this order, the Internet of things, big data, real-time databases, local connectivity, mobile connection payments, autonomous vehicles, tourism intelligence platform, semantic web and open data. All of these technologies will reach their highest level of impact in $2-5$ years, except open data $(5-10$ years) and autonomous vehicles (over 10 years).

These technologies concur with those identified as being essential for the development of smart cities and STDs (Buhalis \& Amaranggana, 2014; Komninos, 2015; Wang etal., 2013). They are clearly oriented towards real-time data collection and data exploitation through big data techniques for a data-driven management approach. This is because the technologies are mainly based on loT (Internet of Things) and user-generated data which connect the physical with the digital and, according to Gretzel, Werthner, etal. (2015), enable smart tourism to be differentiated from e-tourism.

From the point of view of the tourist experience, the impact of local connectivity and the Internet, usually through Wi-Fi and mobile payments are particularly prominent. With respect to technologies related to sensorial experiences, it is predicted that augmented reality will be more relevant than virtual reality, although the degree of consensus is lower for the latter. Holographic displays, ambient intelligence and gesture control are perceived as having a medium level of importance with a maximum level of impact in 5-10 years. In spite of its high media coverage, the wearables group has been valued with a medium level of importance and a maximum level of impact in 2-5 years (smartwatches) or 5-10 years (smart glasses). On the other hand, the level of consensus with respect to digital security is not high. It is considered to have a medium level of importance as is the case of fingerprint biometrics, despite the expectations that this technology will facilitate travel and tourism.

The impact of data technologies such as the enterprise service bus, deep learning or open data will peak in around 5-10 years. The analysis of the assessment of technologies related to data management provides two remarkable conclusions: (i) there is a clear perception of smart destinations as massive data generators and (2) it is believed that those technologies that help to process and understand these data, generating knowledge and better supporting decision-making processes in the destination, will have a high impact. Therefore, it is not only a case of the destination generating data (big data) which are made public (open data) but the destination must be able to process these data in real time and fully exploit them. Therefore, both the semantic web and applications that generate knowledge, such as opinion mining, are important. However, the low impact of technologies related to open data, such as Web Mashups, suggest that the changes envisioned in tourism destination management are based on new approaches to the management of information and knowledge, favouring the internal use of the data by the destination for decision-making over an approach where entrepreneurs propose innovative business models based on the development of services and applications that make intensive use of data. This approach is in line with the forecasts of the economic impact that the reuse of open data will generate. For example, according to the World Bank (2014), the estimated economic benefit to be gained from the reuse of open data in 2020 is 200 billion euros, that is, $1.7 \%$ of the European Union's GDP. 
On the other hand, the database technology expected to have the highest impact is real-time databases, while others, such as graph or document databases, have not been considered to be as relevant. This highlights the importance of the smart destination as a data generator in real time through different sensors and the need for the appropriate processing of these data.

Finally, other technologies, such as robots and UAVs will have a high to medium impact, and, in the long term, so will autonomous vehicles. 3D printing technology, which is currently in full hype, will have a medium level of impact in 5-10 years, and cryptocurrencies will have a low impact and an uncertain evolution, although there is a low level of consensus.

\section{Discussion and conclusions}

The analysis carried out enables us to conclude that the evolution of ICTs is contributing to the shaping of a new scenario for tourism destination management, which requires different management approaches, the most notable being the STD approach. However, this is a very ambitious approach which still suffers from a certain degree of conceptual imprecision and is carried out easily from an institutional point of view or from the perspective of the technological companies' interests. In the same way as ICTs, the STD is experiencing its own hype cycle and has generated high expectations in countries such as Spain or China. Therefore, it is advisable to determine the extent to which this approach is appropriate for adapting destinations to the digitalisation of the tourism activity in all phases of the travel cycle.

The scientific literature and the opinion of the experts ratify the relevance of the STD approach for transforming destination management. There are undeniable advantages to be gained through, among other factors, the incorporation of ICTs. Everything seems to indicate that destination management is evolving towards a technology and data-driven scenario that will reach its peak in the medium term. However, the main barriers hindering the evolution towards the STD approach are found at the strategicrelational level and give governance a fundamental role in reinforcing the knowledge and innovative capacity of destinations as a preliminary step in the efficient development of an STD strategy.

Therefore, the challenge of the STD resides more in governance than technology, highlighting key aspects for the redesign of the functions of the DMOs, which are derived from the research carried out:

- The STD model should be adapted to the needs and resources and the territorial and tourist context of each destination. In view of the varied and growing range of technologies available, the implementation of ICTs requires a previous prioritisation of the needs and possibilities of destination management.

- The technological evolution highlights the priority of reinforcing new capacities in the DMOs in order to facilitate the application of smart solutions and further the analysis and exploitation of data, in collaboration with the tourism companies in the destination. This means that structural limitations have to be overcome in order to innovate and apply the ICTs in the DMOs.

- The opportunity to develop a systemic management approach, which allows feedback from all strategic-relational, instrumental and applied levels. This aspect requires greater coordination between the public and private agents of the destination. Without a higher degree of cooperation on a local scale, the successful development of an STD is improbable.

Using ICT implementation as an evolutionary process (Yuan, Gretzel, \& Fesenmaier, 2006), DMOs should approach their adaptation to technological evolution in line with their needs, resources and capacities. The global nature of the STD models (which encompass everything from innovation to sustainability, including accessibility and a state-of-the-art technological infrastructure) makes them unachievable for many destinations. They can only be used as a management reference when based on indicators adapted to each territorial and tourism context, or as a national and international standard, an aspect that is relatively highly valued by the experts.

The possibilities for technological evolution widely surpass the management capacities of the DMOs. This gap requires changes in the structure and organisation of the DMOs or more imaginative work formulas through the externalisation of services at more affordable prices (for example, software as a service) or agreements with tourist and technological operators. This imbalance is also manifested in terms of the capacity to invest and to control the information that the destinations aspire to transform into knowledge. The large volumes of information associated with big data are usually owned by the large technological or tourism operators, and it is not easy to access or exploit the data to benefit the destinations. On another level, the data derived from tourist demand are conditioned by privacy laws and there is a reticence to share the data of tourist service users.

From a systemic point of view, the integration of destinations in the global digital tourism ecosystem, dominated by large technological and tourism operators, is at stake, as the capacity to adapt constitutes a source of competitive advantage. In this respect, the STD strategy makes sense as it is a process which favours innovation and the consolidation of true learning destinations which have to adopt a systemic approach such as that proposed in Figure 1, where smart solutions do not constitute isolated initiatives but act as catalysts for improving innovation and cooperation between stakeholders.

However, the structural problems that characterise tourism destinations hinder the evolution towards the STD approach. These problems include the predominance of small- and medium-sized companies, the lack of leadership, the lack of a culture of collaboration, the difficulties for innovation and the presence of proprietary software which make interoperability difficult from the point of view of the destination. On the other hand, an appropriate STD strategy can contribute to overcoming these problems as smart solutions help to promote more ambitious collaboration processes, beginning with the breaking down of the structure of the information into departmental silos, like government bodies. Obviously, destination managers should not adopt all of the available technologies, although deciding which technologies to incorporate into the management model is not an easy task as it is not simple to define a technological roadmap on a destination level. Nevertheless, it is intelligent to steer the technological implementation in line with the priority needs of the destination and not according to an imitative strategy or the persuasive power of the technology providers. Furthermore, creativity and the capacity to innovate can make up for the deficit in factors such as investment. By way of example, there are many cases of digital marketing and social media.

Consequently, the new scenario will broaden the differences between the management of the destinations, favouring those with more agile organisational structures, more prone to public-private collaboration and better equipped in terms of economic and human resources. The connectivity infrastructures and the deployment of sensors will be preferred in medium to large urban environments while those destinations with a smaller population and tourism activity will have a competitive disadvantage. However, the smartness of destinations will not be conditioned exclusively by technological availability because a strategy that is shared by all of the actors in the destination will be essential in order to take full advantage of the opportunities generated by the technological evolution, with solutions adapted to each territorial and tourism context.

Finally, it is important to point out the limitations of this research. First, the approach is ambitious because it addresses a highly complex issue such as the evolution of a large number of technologies, the majority of which are important enough to be studied exclusively. This means that an in-depth analysis of each technology cannot be made but an overall view can be given in order to provide a better understanding of the new scenario for tourism destination management that is fundamentally, although not exclusively, derived from technological evolution. Consequently, the results of the Delphi technique have a qualitative, general and illustrative value derived from a prospective exercise which does not provide specific answers for all of the technologies analysed. The complexity of the issue also gives rise to doubts about the representativeness of the experts, who cannot easily be specialists 
in all of the technologies considered. However, the inclusion of the glossary in the questionnaire has assisted the experts in their responses for many of the items. Nevertheless, from the point of view of assessing the STD approach, the panel is able to provide an expert view of an issue which is difficult to separate from its media and institutional nature. Therefore, we can conclude that the STD approach is feasible and constitutes an interesting research topic. This article has not studied the processes of adopting the technology and the role played by the different stakeholders in depth: this aspect has renewed importance for the DMOs in the light of the possibilities that the ICTs offer to transform tourism destination management.

\section{Acknowledgements}

This research has been carried out within the framework of the project "New approaches for tourism destinations planning and management: conceptualization, case studies and problems. Definition of smart tourist destinations models" (CSO2014-59193-R) under the Spanish National R\&D\&I Plan financed by the Ministry of Economy and Competitiveness.

\section{Disclosure statement}

No potential conflict of interest was reported by the authors.

\section{Supplemental data}

Supplemental data for this article can be accessed at https://doi.org/10.1080/13683500.2017.1388771 .

\section{References}

Angeloni , S. (2016). A tourist kit "made in Italy": An "intelligent" system for implementing new generation destination cards. Tourism Management, 52, 187-209. doi:10.1016/j.tourman.2015.06.011.

Baggio , R., \& Scaglione , M. (2017). Strategic Visitor Flows (SVF) analysis using mobile data. In R.Schegg \& B.Stangl (Eds.), Information and communication technologies in tourism 2017 (pp. 145-157). Cham: Springer International Publishing. Retrieved from http://link.springer.com/10.1007/978-3-319-51168-9_11

Benckendorff , P., Sheldon, P. J., \& Fesenmaier , D. R. (2014). Tourism information technology (2nd ed.). Wallingford, UK: CABI.

Berger , S., Lehmann , H., \& Lehner , F. (2003). Location-based services in the tourist industry. Information Technology \& Tourism, 5(4), 243-256. doi:10.3727/109830503108751171.

Boes , K., Buhalis , D., \& Inversini , A. (2015). Conceptualising smart tourism destination dimensions. In I.Tussyadiah \& A. Inversini (Eds.), Information and communication technologies in tourism 2015 (pp. 391-403). Cham: Springer International Publishing. Retrieved from http://link.springer.com/10.1007/978-3-319-14343-9_29

Buhalis , D., \& Amaranggana , A. (2014). Smart tourism destinations. In Z.Xiang \& I.Tussyadiah (Eds.), Information and communication technologies in tourism 2014 (pp. 553-564). Cham: Springer International Publishing. Retrieved from http://link.springer.com/10.1007/978-3-319-03973-2_40

Buhalis , D., \& Amaranggana , A. (2015). Smart tourism destinations enhancing tourism experience through personalisation of services. In I.Tussyadiah, \& A. Inversini (Eds.), Information and communication technologies in tourism 2015 (pp. 377-389). Cham: Springer. Retrieved from https://link.springer.com/chapter/10.1007/978-3-319-14343-9_28.

Buhalis, D. (2003). Etourism: Information technology for strategic tourism management. Harlow, UK: Financial Times Prentice Hall.

Buhalis , D., \& Foerste , M. (2015). SOCOMO marketing for travel and tourism: Empowering co-creation of value. Journal of Destination Marketing \& Management, 4(3), 151-161. doi:10.1016/j.jdmm.2015.04.001.

Buhalis , D., \& Law, R. (2008). Progress in information technology and tourism management: 20 years on and 10 years after the Internet - The state of eTourism research. Tourism Management, 29(4), 609-623. doi:10.1016/j.tourman.2008.01.005.

Buhalis, D., \& Matloka , J. (2013). Technology-enabled tourism destination management and marketing. In C.Costa, E.Panyik, D.Buhalis (Eds.), Trends in European tourism planning and organisation (pp. 339-350). Buffalo, NY: Channel View Publications.

Caragliu , A., \& Del Bo , C. (2012). Smartness and European urban performance: Assessing the local impacts of smart urban attributes. Innovation: The European Journal of Social Science Research, 25(2), 97-113. doi:10.1080/13511610.2012.660323.

Cetin , G., Aydogan Cifci , M., Istanbullu Dincer , F., \& Fuchs , M. (2016). Coping with reintermediation: The case of SMHEs. Information Technology \& Tourism, 16(4), 375-392. doi:10.1007/s40558-016-0063-2.

Chung, N., \& Koo , C. (2015). The use of social media in travel information search. Telematics and Informatics, 32(2), 215-229. doi:10.1016/j.tele.2014.08.005. 
Cole , Z. D., Donohoe , H. M., \& Stellefson , M. L. (2013). Internet-based Delphi research: Case based discussion. Environmental Management, 51(3), 511-523. doi:10.1007/s00267-012-0005-5.

Cooper , C., \& Sheldon , P. (2010). Knowledge management in tourism: From databases to learning destinations. In D. G.Pearce, \& R.Butler (Eds.), Tourism research: A 20-20 vision (pp. 215-227). Oxford: Goodfellow Publ.

Del Chiappa , G., \& Baggio , R. (2015). Knowledge transfer in smart tourism destinations: Analyzing the effects of a network structure. Journal of Destination Marketing \& Management, 4(3), 145-150. doi:10.1016/j.jdmm.2015.02.001.

Donohoe , H. M., \& Needham , R. D. (2009). Moving best practice forward: Delphi characteristics, advantages, potential problems, and solutions. International Journal of Tourism Research, 11(5), 415-437. doi:10.1002/jtr.709.

Fenn , J., \& Raskino , M. (2008). Mastering the hype cycle: How to choose the right innovation at the right time. Boston, MA: Harvard Business Press.

Fuchs , M., Höpken , W., \& Lexhagen , M. (2014). Big data analytics for knowledge generation in tourism destinations - A case from Sweden. Journal of Destination Marketing \& Management, 3(4), 198-209. doi:10.1016/j.jdmm.2014.08.002.

Garrod , B., \& Fyall , A. (2000). Managing heritage tourism. Annals of Tourism Research, 27(3), 682-708. doi:10.1016/S01607383(99)00094-8.

Garrod, B., \& Fyall , A. (2004). Revisiting Delphi: The Delphi technique in tourism research. In B. W.Ritchie, P.Burns, \& C.Palmer (Eds.), Tourism research methods. Integrating theory with practice (pp. 85-98). Wallingford,UK: CABI Publishing.

Geels , F. W. (2002). Technological transitions as evolutionary reconfiguration processes: A multi-level perspective and a casestudy. Research Policy, 31(8-9), 1257-1274. doi:10.1016/S0048-7333(02)00062-8.

Giffinger, R., Fertner , C., Kramar , H., Kalasek, R., Pichler-Milanovic, N., \& Meijers , E. (2007). Smart cities: Ranking of European medium-sized cities. Retrieved from European Smart Cites: http://uww.smartcities.eu/download/smart_cities_final_report.pdf

Google. (2014). The 2014 Traveler's Road to Decision. Retrieved from Google: https://umw.thinkwithgoogle.com/consumerinsights/2014-travelers-road-to-decision/.

Graziano, Teresa. (2014). Boosting innovation and development? The italian smart tourism: a critical perspective. European Journal of Geography, 5(4), 6-18.

Greenfield , A. (2013). Against the smart city. NewYork, NY: Do Projects.

Gretzel , U., Sigala , M., Xiang , Z., \& Koo , C. (2015). Smart tourism: Foundations and developments. Electronic Markets, 25(3), 179-188. doi:10.1007/s12525-015-0196-8.

Gretzel , U. (2011). Intelligent systems in tourism. A social science perspective. Annals of Tourism Research, 38(3), 757-779. doi:10.1016/j.annals.2011.04.014

Gretzel , U., Werthner , H., Koo , C., \& Lamsfus , C. (2015). Conceptual foundations for understanding smart tourism ecosystems. Computers in Human Behavior, 50, 558-563. doi:10.1016/j.chb.2015.03.043.

Gretzel , U., Yuan , Y.-L., \& Fesenmaier , D. R. (2000). Preparing for the new economy: Advertising strategies and change in destination marketing organizations. Journal of Travel Research, 39(2), 146-156. doi:10.1177/004728750003900204.

Guo , Y., Liu , H., \& Chai , Y. (2014). The embedding convergence of smart cities and tourism internet of things in China: An advance perspective. Advances in Hospitality and Tourism Research (AHTR), 2(1), 54-69. Retrieved from http://www.ahtrjournal.org/

Hall , C. M., \& Williams , A. M. (2008). Tourism and innovation. NewYork, NY: Routledge.

Hjalager , A.-M. (2015). 100 innovations that transformed tourism. Journal of Travel Research, 54(1), 3-21. doi:10.1177/0047287513516390.

Ivars , J. A., Solsona , F. J., \& Giner , D. (2016). Gestión turística y tecnologías de la información y la comunicación (TIC): EI nuevo enfoque de los destinos inteligentes. [Tourism management and Information and Communication Technologies (ICTs): The smart destinations new approach]. Documents d'Anàlisi Geogràfica, 62(2), 327-346. doi:10.5565/rev/dag.285.

Jolly , D., \& Dimanche , F. (2009). Investing in technology for tourism activities: Perspectives and challenges. Technovation, 29(9), 576-579. doi:10.1016/j.technovation.2009.05.004. 
Jovicic , D. Z. (2016). Key issues in the conceptualization of tourism destinations. Tourism Geographies, $18(4)$, $445-457$. doi:10.1080/14616688.2016.1183144.

Kanama , D., Kondo , A., \& Yokoo , Y. (2008). Development of technology foresight: Integration of technology roadmapping and the Delphi method. International Journal of Technology Intelligence and Planning, 4(2), 184. doi:10.1504/IJTIP.2008.018316.

Kelly, K. (2016). The inevitable: Understanding the 12 technological forces that will shape our future. NewYork, NY: Viking

Kitchin , R. (2015). Making sense of smart cities: Addressing present shortcomings. Cambridge Journal of Regions, Economy and Society, 8(1), 131-136. doi:10.1093/cjres/rsu027.

Komninos , N. (2002). Intelligent cities: Innovation, knowedge systems, and digital spaces. NewYork, NY: Spon Press.

Komninos, N. (2015). The age of intelligent cities: Smart environments and innovation-for-all strategies (1st ed.). NewYork, NY: Routledge, Taylor \& Francis Group.

Koo , C., Shin , S., Gretzel , U., Canon , W., \& Chung , N. (2016). Conceptualization of smart tourism destination competitiveness. Asia Pacific Journal of Information Systems, 26(4), 367-384. doi:10.14329/apjis.2016.26.4.561

Landeta , J., Barrutia , J., \& Lertxundi , A. (2011). Hybrid Delphi: A methodology to facilitate contribution from experts in professional contexts. The Delphi Technique: Past, Present, and Future Prospects, 78(9), 1629-1641. doi:10.1016/j.techfore.2011.03.009.

Landeta , J. (1999). El método Delphi: Una técnica de previsión del futuro [The Delphi method: A technique for forecasting the future]. Barcelona: Ariel.

Law , R., Buhalis , D., \& Cobanoglu , C. (2014). Progress on information and communication technologies in hospitality and tourism. International Journal of Contemporary Hospitality Management, 26(5), 727-750. doi:10.1108/IJCHM-08-2013-0367.

Li , Y., Hu , C., Huang , C., \& Duan , L. (2017). The concept of smart tourism in the context of tourism information services. Tourism Management, 58, 293-300. doi:10.1016/j.tourman.2016.03.014.

March , H., \& Ribera-Fumaz, R. (2016). Smart contradictions: The politics of making Barcelona a self-sufficient city. European Urban and Regional Studies, 23(4), 816-830. doi:10.1177/0969776414554488.

Marine-Roig , E., \& Anton Clavé , S. (2015). Tourism analytics with massive user-generated content: A case study of Barcelona. Journal of Destination Marketing \& Management, 4(3), 162-172. doi:10.1016/j.jdmm.2015.06.004.

Munar , A. M., \& Jacobsen , J.K.S. (2014). Motivations for sharing tourism experiences through social media. Tourism Management, 43, 46-54. doi:10.1016/j.tourman.2014.01.012.

Neuhofer , B., Buhalis , D., \& Ladkin , A. (2012). Conceptualising technology enhanced destination experiences. Journal of Destination Marketing \& Management, 1(1-2), 36-46. doi:10.1016/j.jdmm.2012.08.001.

Niininen , O., March , R., \& Buhalis , D. (2006). Consumer centric tourism marketing. In D.Buhalis \& C.Costa (Eds.), Tourism management dynamics: Trends, management and tools (pp. 175-186). London: Buttterworth Heinemann.

Okoli , C., \& Pawlowski , S. D. (2004). The Delphi method as a research tool: An example, design considerations and applications. Information \& Management, 42(1), 15-29. doi:10.1016/j.im.2003.11.002.

Pearce, D. G. (2014). Toward an integrative conceptual framework of destinations. Journal of Travel Research, 53(2), $141-153$. doi:10.1177/0047287513491334.

Perez, C. (2002). Technological revolutions and financial capital: The dynamics of bubbles and golden ages. Cheltenham: Edward Elgar Publishing

Pesonen , J., \& Lampi , M. (2016). Utilizing open data in tourism. e-Review of Tourism Research. Enter 2016, Vol. 7, Research Notes. Retrieved from http://ertr.tamu.edu/enter-2016-volume-7-research-notes/

Poon , Auliana. (1993). Tourism, technology and competitive strategies. Wallindorf: CAB International.

Rogers , E. M. (1962). Diffusion of innovations. NewYork, NY: Free Press of Glencoe.

Saraniemi , S., \& Kylanen , M. (2011). Problematizing the concept of tourism destination: An analysis of different theoretical approaches. Journal of Travel Research, 50(2), 133-143. doi:10.1177/0047287510362775.

Schianetz , K., Kavanagh , L., \& Lockington , D. (2007). The learning tourism destination: The potential of a learning organisation approach for improving the sustainability of tourism destinations. Tourism Management, 28(6), 1485-1496. doi:10.1016/j.tourman.2007.01.012. 
SEGITTUR. (2015). Informe destinos turísticos inteligentes: construyendo el futuro [Report on smart tourism destinations: building the future]. Retrieved from

Segittur:http://mww.segittur.es/opencms/export/sites/segitur/.content/galerias/descargas/proyectos/Libro-Blanco-DestinosTursticos-Inteligentes-construyendo-el-futuro.pdf

Sheldon , P. J. (1997). Tourism information technology. NewYork, UK: CAB International.

Sigala , M., Christou , E., \& Gretzel , U. (2012). Social media in travel, tourism and hospitality: Theory, practice and cases. Burlington, VT: Ashgate Pub.

Townsend, A. M. (2013). Smart cities: Big data, civic hackers, and the quest for a new utopia. NewYork, NY: W.W.Norton Inc.

Tussyadiah , I. P., Wang , D., \& Jia , C. (2017). Virtual reality and attitudes toward tourism destinations. In R.Schegg, \& B.Stangl (Eds.), Information and communication technologies in tourism 2017 (pp. 229-239). Cham: Springer International Publishing. Retrieved from http://link.springer.com/10.1007/978-3-319-51168-9_17

Vanolo , A. (2014). Smartmentality: The smart city as disciplinary strategy. Urban Studies, 51(5), 883-898. doi:10.1177/0042098013494427.

Wang , D., Li , X. (Robert), \& Li , Y. (2013). China's "smart tourism destination" initiative: A taste of the service-dominant logic. Researching Destination Experiences, 2(2), 59-61. doi:10.1016/j.jdmm.2013.05.004.

Wang , X. Li , X (Robert), Zhen , F., \& Zhang , J. (2016). How smart is your tourist attraction? Measuring tourist preferences of smart tourism attractions via a FCEM-AHP and IPA approach. Tourism Management, 54, 309-320. doi:10.1016/j.tourman.2015.12.003.

World Bank. (2014). Open data for economic growth. Retrieved from World Bank:

http://www.worldbank.org/content/dam/Worldbank/document/Open-Data-for-Economic-Growth.pdf

Xiang , Z., Tussyadiah , I., \& Buhalis , D. (2015). Smart destinations: Foundations, analytics, and applications. Journal of Destination Marketing \& Management, 4(3), 143-144. doi:10.1016/j.jdmm.2015.07.001.

Yuan , Y.-L., Gretzel , U., \& Fesenmaier , D. R. (2006). The role of information technology use in American convention and visitor bureaus. Tourism Management, 27(2), 326-341. doi:10.1016/j.tourman.2004.12.001.

\section{APPENDIX 1}

Table A1. Forecast of impact of technologies on tourism.

\begin{tabular}{|c|c|c|c|c|c|c|c|c|c|}
\hline & Impact & $\mathrm{L} \%$ & $M \%$ & $\mathrm{H} \%$ & & Impact & L \% & $M \%$ & $\mathrm{H} \%$ \\
\hline \multirow{7}{*}{ Connectivity } & \begin{tabular}{|l|} 
Internet IPv6z (Internet \\
Protocol Version 6)
\end{tabular} & 27.27 & 18.18 & 54.55 & \multirow{6}{*}{$\begin{array}{l}\text { Identity, } \\
\text { Payments, } \\
\text { Security }\end{array}$} & Fingerprint Biometrics & 27.27 & 45.45 & 27.27 \\
\hline & Internet of Things (loT) & 0.00 & 4.55 & 95.45 & & $\begin{array}{l}\text { Cryptocurrencies } \\
\text { (Bitcoin, Litecoin, ...) }\end{array}$ & 40.91 & 36.36 & 22.73 \\
\hline & $\begin{array}{l}\text { Fi-Ware (Future } \\
\text { Internet-ware) }\end{array}$ & 13.64 & 36.36 & 50.00 & & $\begin{array}{l}\text { Near Field } \\
\text { Communications (NFC) } \\
\text { Payments }\end{array}$ & 0.00 & 36.36 & 63.64 \\
\hline & $\begin{array}{l}\text { Portable Wi-Fi (Mi-Fi, } \\
\ldots)\end{array}$ & 9.09 & 22.73 & 68.18 & & $\begin{array}{l}\text { Mobile Connection } \\
\text { Payments }\end{array}$ & 4.55 & 13.64 & 81.82 \\
\hline & Mobile Connectivity $5 \mathrm{G}$ & 4.55 & 31.82 & 63.64 & & $\begin{array}{l}\text { Wearables/Cards } \\
\text { NFC/RFID }\end{array}$ & 0.00 & 36.36 & 63.64 \\
\hline & $\begin{array}{l}\text { Local Connectivity (Wi- } \\
\mathrm{Fi}, \mathrm{Li}-\mathrm{Fi}, \ldots)\end{array}$ & 0.00 & 18.18 & 81.82 & & Digital Security & 9.09 & 45.45 & 45.45 \\
\hline & $\begin{array}{l}\text { Bluetooth Low Energy } \\
(4.0)\end{array}$ & 4.55 & 40.91 & 54.55 & \multirow{5}{*}{$\begin{array}{l}\text { Sensorial } \\
\text { experiences }\end{array}$} & Augmented Reality & 0.00 & 36.36 & 63.64 \\
\hline \multirow{3}{*}{ Wearables } & $\begin{array}{l}\text { Wearable Google } \\
\text { Glass \& the like }\end{array}$ & 22.73 & 59.09 & 18.18 & & Virtual Reality & 4.55 & 45.45 & 50.00 \\
\hline & Wearable Smartwatch & 22.73 & 59.09 & 18.18 & & $\begin{array}{l}\text { Volumetric and } \\
\text { Holographic Displays }\end{array}$ & 18.18 & 45.45 & 36.36 \\
\hline & Other Wearables & 31.82 & 40.91 & 27.27 & & Ambient Intelligence & 0.00 & 61.90 & 38.10 \\
\hline & & & & & & Gesture control & 22.73 & 50.00 & 27.27 \\
\hline
\end{tabular}




\begin{tabular}{|c|c|c|c|c|c|c|c|c|c|}
\hline & Impact & L \% & $\mathrm{M} \%$ & $\mathrm{H} \%$ & & Impact & L \% & $M \%$ & $\mathrm{H} \%$ \\
\hline \multirow{11}{*}{\begin{tabular}{|l} 
Data \\
Management
\end{tabular}} & Open Data & 4.55 & 22.73 & 72.73 & \multirow{5}{*}{$\begin{array}{l}\text { Data } \\
\text { Management } \\
\text { (continue) }\end{array}$} & $\begin{array}{l}\text { Recommendations } \\
\text { System }\end{array}$ & 4.55 & 31.82 & 63.64 \\
\hline & Mashups & 14.29 & 52.38 & 33.33 & & Deep Learning & 9.09 & 40.91 & 50.00 \\
\hline & Big Data & 0.00 & 13.64 & 86.36 & & Graph Database & 28.57 & 42.86 & 28.57 \\
\hline & Text Mining & 0.00 & 36.36 & 63.64 & & $\begin{array}{l}\text { Document-Oriented } \\
\text { Database }\end{array}$ & 19.05 & 66.67 & 14.29 \\
\hline & Web Mining & 0.00 & 40.91 & 59.09 & & $\begin{array}{l}\text { ESB (Enterprise Service } \\
\text { Bus) }\end{array}$ & 9.52 & 28.57 & 61.90 \\
\hline & Opinion Mining & 4.55 & 27.27 & 68.18 & \multirow{5}{*}{$\begin{array}{l}\text { Other } \\
\text { technologies }\end{array}$} & QR Codes & 45.45 & 40.91 & 13.64 \\
\hline & Question Answering & 4.76 & 52.38 & 42.86 & & 3D Printing & 18.18 & 68.18 & 13.64 \\
\hline & $\begin{array}{l}\text { Tourism Intelligence } \\
\text { Platform }\end{array}$ & 4.55 & 18.18 & 77.27 & & $\begin{array}{l}\text { Commercial UAVs } \\
\text { (Drones) }\end{array}$ & 18.18 & 22.73 & 59.09 \\
\hline & $\begin{array}{l}\text { Complex Events } \\
\text { Processing }\end{array}$ & 10.00 & 45.00 & 45.00 & & Robots & 13.64 & 18.18 & 68.18 \\
\hline & Real-Time Databases & 0.00 & 15.00 & 85.00 & & Autonomous Vehicles & 0.00 & 18.18 & 81.82 \\
\hline & $\begin{array}{l}\text { Semantic Web (WEB } \\
3.0)\end{array}$ & 4.55 & 22.73 & 72.73 & & & & & \\
\hline
\end{tabular}

Notes: L: low; M: medium; $\mathrm{H}$ : high. Maximum values shaded in grey.

Table A2. Forecast of maximum impact/use of technologies in tourism.

\begin{tabular}{|c|c|c|c|c|c|c|c|c|c|c|c|c|c|}
\hline & Forecasting & T\% & St \% & Mt \% & Lt \% & U \% & & Forecasting & $\mathrm{T} \%$ & St \% & Mt \% & Lt \% & U\% \\
\hline \multirow{7}{*}{ Connectivity } & \begin{tabular}{|l} 
Internet \\
IPv6z \\
(Internet \\
Protocol \\
Version 6)
\end{tabular} & 13.6 & 40.9 & 31.8 & 9.0 & 4.5 & \multirow{6}{*}{\begin{tabular}{|l} 
Identity, \\
Payments, \\
Security
\end{tabular}} & $\begin{array}{l}\text { Fingerprint } \\
\text { Biometrics }\end{array}$ & $\mid 18.1$ & 50.0 & 22.7 & 9.09 & 0.00 \\
\hline & \begin{tabular}{|l|} 
Internet of \\
Things (loT)
\end{tabular} & 9.09 & 40.91 & $\mid 31.82$ & $\mid 18.18$ & 0.00 & & $\begin{array}{l}\text { Cryptocurrencies } \\
\text { (Bitcoin, Litecoin, } \\
\text { ‥) }\end{array}$ & 9.09 & 4.55 & 22.73 & 36.36 & 27.27 \\
\hline & $\begin{array}{l}\text { Fi-Ware } \\
\text { (Future } \\
\text { Internet- } \\
\text { ware) }\end{array}$ & 0.00 & 9.09 & 45.45 & 31.82 & 13.6 & & $\begin{array}{l}\text { Near Field } \\
\text { Communications } \\
\text { (NFC) Payments }\end{array}$ & 9.09 & 59.09 & 27.27 & 4.55 & 0.00 \\
\hline & $\begin{array}{l}\text { Portable } \\
\text { Wi-Fi (Mi- } \\
\mathrm{Fi}, \ldots \text { ) }\end{array}$ & 45.45 & 50.00 & 4.55 & 0.00 & 0.00 & & $\begin{array}{l}\text { Mobile Connection } \\
\text { Payments }\end{array}$ & 31.82 & 54.55 & 13.64 & 0.00 & 0.00 \\
\hline & \begin{tabular}{|l|} 
Mobile \\
Connectivity \\
$5 G$
\end{tabular} & 0.00 & 68.18 & |31.82 & 0.00 & 0.00 & & $\begin{array}{l}\text { Wearables/Cards } \\
\text { NFC/RFID }\end{array}$ & 9.09 & 63.64 & 18.18 & 9.09 & 0.00 \\
\hline & \begin{tabular}{|l|} 
Local \\
Connectivity \\
(Wi-Fi, Li- \\
$\mathrm{Fi}, \ldots$ )
\end{tabular} & 40.91 & 54.55 & 4.55 & 0.00 & 0.00 & & Digital Security & 40.91 & 45.45 & 4.55 & 4.55 & 4.55 \\
\hline & \begin{tabular}{|l|} 
Bluetooth \\
Low Energy \\
$(4.0)$
\end{tabular} & 27.27 & 54.55 & 18.18 & 0.00 & 0.00 & \multirow{5}{*}{$\begin{array}{l}\text { Sensorial } \\
\text { experiences }\end{array}$} & $\begin{array}{l}\text { Augmented } \\
\text { Reality }\end{array}$ & 22.73 & 54.55 & 18.18 & 4.55 & 0.00 \\
\hline \multirow{3}{*}{ Wearables } & \begin{tabular}{|l} 
Wearable \\
Google \\
Glass \& the \\
like
\end{tabular} & 9.52 & 14.29 & $\mid 33.33$ & $\mid 28.57$ & 14.29 & & Virtual Reality & 18.18 & 45.45 & 27.27 & 9.09 & 0.00 \\
\hline & $\begin{array}{l}\text { Wearable } \\
\text { Smartwatch }\end{array}$ & 18.18 & 54.55 & |22.73 & 4.55 & 0.00 & & $\begin{array}{l}\text { Volumetric and } \\
\text { Holographic } \\
\text { Displays }\end{array}$ & 4.55 & 22.73 & 36.36 & 27.27 & 9.09 \\
\hline & \begin{tabular}{|l} 
Other \\
Wearables
\end{tabular} & 22.73 & 27.27 & 40.91 & 4.55 & 4.55 & & \begin{tabular}{|l} 
Ambient \\
Intelligence
\end{tabular} & 0.00 & 4.76 & 57.14 & 38.10 & 0.00 \\
\hline \multirow{4}{*}{ ב } & & & & & & & & Gesture control & 4.55 & 4.55 & 59.09 & 27.27 & 4.55 \\
\hline & Open Data & 13.64 & 27.27 & $\mid 50.00$ & 4.55 & 4.55 & \multirow{3}{*}{ Data } & $\begin{array}{l}\text { Recommendations } \\
\text { System }\end{array}$ & 45.45 & 31.82 & 22.73 & 0.00 & 0.00 \\
\hline & Mashups & 42.86 & 33.33 & 19.05 & 4.76 & 0.00 & & Deep Learning & 0.00 & 36.36 & 50.00 & 4.55 & 9.09 \\
\hline & Big Data & 36.36 & 45.45 & 18.18 & 0.00 & 0.00 & & Graph Database & 23.81 & 42.86 & 23.81 & 4.76 & 4.76 \\
\hline
\end{tabular}




\begin{tabular}{|c|c|c|c|c|c|c|c|c|c|c|c|c|c|}
\hline & \begin{tabular}{|l|} 
Forecasting \\
\end{tabular} & $\mathrm{T} \%$ & St \% & Mt \% & Lt \% & $\mathrm{U} \%$ & $\begin{array}{l}\text { Management } \\
\text { (continue) }\end{array}$ & Forecasting & $\mathrm{T} \%$ & St \% & Mt \% & \begin{tabular}{|l|} 
Lt $\%$ \\
\end{tabular} & $\mathrm{U} \%$ \\
\hline \multirow{8}{*}{$\begin{array}{l}\text { Data } \\
\text { Management }\end{array}$} & Text Mining & 36.36 & 50.00 & 13.64 & 0.00 & 0.00 & & $\begin{array}{l}\text { Document- } \\
\text { Oriented } \\
\text { Database }\end{array}$ & 18.18 & 45.45 & 27.27 & 4.55 & 4.55 \\
\hline & Web Mining & 50.00 & 31.82 & 13.64 & 0.00 & 4.55 & & $\begin{array}{l}\text { ESB (Enterprise } \\
\text { Service Bus) }\end{array}$ & 4.55 & 9.09 & 77.27 & 4.55 & 4.55 \\
\hline & \begin{tabular}{|l|} 
Opinion \\
Mining
\end{tabular} & 59.09 & 18.18 & 22.73 & 0.00 & 0.00 & \multirow{5}{*}{$\begin{array}{l}\text { Other } \\
\text { technologies }\end{array}$} & QR Codes & 81.82 & 13.64 & 0.00 & 0.00 & 4.55 \\
\hline & \begin{tabular}{|l|} 
Question \\
Answering \\
\end{tabular} & 13.64 & 45.45 & 22.73 & 4.55 & 13.64 & & 3D Printing & 9.09 & 36.36 & 45.45 & 9.09 & 0.00 \\
\hline & $\begin{array}{l}\text { Tourism } \\
\text { Intelligence } \\
\text { Platform }\end{array}$ & 13.64 & 40.91 & 36.36 & 9.09 & 0.00 & & $\begin{array}{l}\text { Commercial UAVs } \\
\text { (Drones) }\end{array}$ & 13.64 & 68.18 & 13.64 & 4.55 & 0.00 \\
\hline & \begin{tabular}{|l|} 
Complex \\
Events \\
Processing \\
\end{tabular} & 14.29 & 28.57 & 42.86 & 4.76 & 9.52 & & Robots & 0.00 & 9.09 & 63.64 & $\mid 18.18$ & 9.09 \\
\hline & \begin{tabular}{|l|} 
Real-Time \\
Databases \\
\end{tabular} & 14.29 & 57.14 & 23.81 & 0.00 & 4.76 & & \begin{tabular}{|l} 
Autonomous \\
Vehicles
\end{tabular} & 0.00 & 0.00 & 40.91 & 59.09 & 0.00 \\
\hline & $\begin{array}{l}\text { Semantic } \\
\text { Web (WEB } \\
3.0 \text { ) }\end{array}$ & 18.18 & 45.45 & 27.27 & 9.09 & 0.00 & & & & & & & \\
\hline
\end{tabular}

Notes: T: today, St: short term; Mt: medium term; Lt: long term; U: uncertain. Maximum values shaded in grey. The highest values appear in bold.

\section{APPENDIX 2. Delphi questionnaire contents.}

The questionnaire that you are going to respond to is divided into two parts:

1. THE IMPACT OF ICTS ON THE MANAGEMENT/MARKETING OF TOURIST DESTINATIONS.

2. THE SMART DESTINATION APPROACH: ANALYSIS AND EVALUATION.

QUESTION 1. Please enter your FULL NAME

Now you will be asked to respond to questions regarding Part 1: THE IMPACT OF ICTs ON THE MANAGEMENT/MARKETING OF TOURIST DESTINATIONS.

\begin{tabular}{|c|c|c|}
\hline \multicolumn{3}{|c|}{$\begin{array}{l}\text { QUESTION 2. In this question we will show you different technologies. Please tell us your opinion of their degree of impact on } \\
\text { tourism and when you consider these technologies will reach their maximum level of impact/use in the tourism sector. }\end{array}$} \\
\hline \multirow{2}{*}{ Technologies } & \begin{tabular}{|l|} 
What is the degree of impact these \\
technologies will have on tourism?
\end{tabular} & When do you expect their maximum level of impact? \\
\hline & Dk/Da-Low-Medium-High & $\begin{array}{l}\text { Dk/Da-Today-Short term (2 years)- Medium term (5 years)- } \\
\text { Long term (more than } 10 \text { years)- Uncertain }\end{array}$ \\
\hline \multicolumn{3}{|l|}{$\begin{array}{l}\text { INTERNET IPv6z } \\
\text { (Internet Protocol } \\
\text { Version 6) } \\
\end{array}$} \\
\hline $\begin{array}{l}\text { INTERNET OF THINGS } \\
\text { (loT) }\end{array}$ & \multicolumn{2}{|c|}{$\begin{array}{l}\text { The incorporation of the capacity to be digitally identified and to exchange data across the Internet into } \\
\text { all types of objects. }\end{array}$} \\
\hline $\begin{array}{l}\text { FI-WARE (Future } \\
\text { Internet-ware) }\end{array}$ & \multicolumn{2}{|c|}{$\begin{array}{l}\text { The Fiware Community Mission is "to build an open sustainable ecosystem around public, royalty-free } \\
\text { and implementation-driven software platform standards that will ease the development of new Smart } \\
\text { Applications in multiple sectors" }\end{array}$} \\
\hline $\begin{array}{l}\text { Portable Wi-Fi (Mi-Fi, } \\
\ldots)\end{array}$ & \multicolumn{2}{|c|}{ Portable devices able to create a small Wi-Fi network instantaneously and anywhere. } \\
\hline $\begin{array}{l}\text { MOBILE } \\
\text { CONNECTIVITY } 5 G\end{array}$ & \multicolumn{2}{|c|}{$\begin{array}{l}\text { Next generation of mobile connectivity not yet defined which aims to go beyond the significant increase } \\
\text { in data transmission speed, adding improvements such as lower latencies, higher reliability and the use } \\
\text { of multiple frequencies for the better use of the radio spectrum. }\end{array}$} \\
\hline $\begin{array}{l}\text { LOCAL } \\
\text { CONNECTIVITY (Wi-Fi, } \\
\text { Li-Fi, ...) }\end{array}$ & \multicolumn{2}{|c|}{$\begin{array}{l}\text { Provision of Internet connectivity for mobile devices and other computers using mid-range } \\
\text { communications infrastructure and provided by private houses, shops, museums, etc. Future } \\
\text { standards such as Li-Fi are included. }\end{array}$} \\
\hline
\end{tabular}


QUESTION 2. In this question we will show you different technologies. Please tell us your opinion of their degree of impact on tourism and when you consider these technologies will reach their maximum level of impact/use in the tourism sector.

\begin{tabular}{|l||l}
\hline BLUETOOTH LOW & The innovation with respect to previous versions is the addition of services that require very little \\
ENERGY (4.0) & energy power, allowing the creation of smart tags, i-Beacons, automatic recognition of computers
\end{tabular} personal sensing, etc.

WEARABLE GOOGLE Devices able to provide services similar to those provided by smartphones with certain advantages with GLASS AND THE LIKE

WEARABLE

SMARTWATCH respect to hand-free usability (augmented reality, video recording, etc.)

Watches with tactile graphic screen able to execute IT applications in order to provide services such as notifications, sensorisation, etc. They are usually wirelessly connected to a Smartphone.

OTHER WEARABLES (Belts, bracelets, etc.)

FINGERPRINT

BIOMETRICS

Electronic "wearable" devices different to those in the previous categories (belts, bracelets, necklaces, cufflinks, ...) with a wide range of functions (readings of vital signs, movement, notifications, etc.).

CRYPTOCURRENCIES (Bitcoin, Litecoin, ...)

NEAR FIELD

COMMUNICATIONS-

(NFC)

MOBILE CONNECTION

PAYMENTS

Digital fingerprint solutions.

A digital or virtual currency that uses cryptography for security not issued by any central authority.

NFC allows two devices placed within a few centimetres of each other to exchange data. In order for this to work, both devices must be equipped with an NFC chip.

Payments using smartphones (3G/4G, etc.).

Wearables/Cards

NFC/RFID

Devices with NFC or RFID (Radio-frequency identification) capable of incorporating a unique identity for accessing services, access control, payments, etc. (example: smartcards).

DIGITAL SECURITY

Security tools (cybersecurity, operational safety technology, information security, physical security devices, etc.) to protect businesses and their devices, including loT.

AUGMENTED $\quad$ An enhanced version of reality created by the use of technology to overlay digital information on an REALITY image of something being viewed through a device (such as a smartphone camera)

VIRTUAL REALITY

VOLUMETRIC AND

HOLOGRAPHIC

DISPLAYS

An artificial environment which is experienced through sensory stimuli (such as sights and sounds)

provided by a computer and in which one's actions partially determine what happens in the environment

AMBIENT

INTELLIGENCE

GESTURE CONTROL

QR CODES

3D PRINTING

Display technology that reconstructs the light field of a three-dimensional scene in space with coherent light. No special glasses are required.

Digital environments that proactively support people's needs.

The ability to recognize and interpret movements of the human body in order to interact with and control a computer system without direct physical contact

Representation of digital information through graphic codes that can be captured and decoded through mobile phone cameras.

Technologies that allow the general public to generate 3D objects with different materials. Includes fields from office automation with conventional printers to designs commissioned by third parties (custom).

COMMERCIAL UAVs

(Drones)

Use of unmanned aerial vehicles to provide services such as the transport of goods, surveillance, etc.

ROBOTS

Automatic programmable machines capable of carrying out complex tasks and replacing human beings.

AUTONOMOUS

VEHICLES (without drivers)

Transport vehicles equivalent to current vehicles but which do not need a human driver, integrating into traffic by way of the sensorisation of the environment.

OPEN DATA

Data that can be reused and redistributed by people or organizations however they wish, without any restrictions

MASHUPS

Web applications that use the content from different sources in order to contributed value added thanks to the use of different APIs.

BIG DATA

Data that require special techniques of analysis due to their large volume, heterogeneity and speed of generation

TEXT MINING

The purpose of Text Mining is to process unstructured (textual) information, extract meaningful numeric indices from the text, and, thus, make the information contained in the text accessible to the various data mining (statistical and machine learning) algorithms

WEB MINING

The data mining techniques application to extract knowledge based on web data.

OPINION MINING

Opinion mining, which is also called sentiment analysis, involves building an automated system to collect and categorize opinions about a product.

QUESTION

ANSWERING

TOURISM

INTELLIGENCE

PLATFORM

An information retrieval system in which a direct answer is expected in response to a submitted query,

rather than a set of references that may contain the answers.

Technological platform on which information relating to tourism activities could be used for tourism intelligence purposes through the collection, analysis and visualization of data. 
QUESTION 2. In this question we will show you different technologies. Please tell us your opinion of their degree of impact on tourism and when you consider these technologies will reach their maximum level of impact/use in the tourism sector.

\begin{tabular}{|l|l|}
\hline \hline $\begin{array}{l}\text { COMPLEXEVENTS } \\
\text { PROCESSING }\end{array}$ & $\begin{array}{l}\text { Method of tracking and analyzing (processing) streams of information (data) about things that happen } \\
\text { (events), and deriving a conclusion from them. }\end{array}$ \\
\hline \hline $\begin{array}{l}\text { REAL-TIME } \\
\text { DATABASES }\end{array}$ & $\begin{array}{l}\text { A database system which uses real-time processing to handle workloads with a constantly changing } \\
\text { state. }\end{array}$ \\
\hline \hline $\begin{array}{l}\text { SEMANTIC WEB (Web } \\
\text { 3.0) }\end{array}$ & $\begin{array}{l}\text { Involves publishing in languages specifically designed for data: Resource Description Framework } \\
\text { (RDF) giving the Web certain "intelligence" to associate some data with others, to make more precise } \\
\text { searches, etc. }\end{array}$ \\
\hline \hline $\begin{array}{l}\text { RECOMMENDATIONS } \\
\text { SYSTEM }\end{array}$ & $\begin{array}{l}\text { Web applications that involve predicting user responses to options based on interest in particular } \\
\text { contents or similarities between users. }\end{array}$ \\
\hline \hline DEEP LEARNING & $\begin{array}{l}\text { Deep Learning, a new area of machine learning, is about learning multiple levels of representation and } \\
\text { abstraction that help to make sense of data such as images, sound, and text }\end{array}$ \\
\hline \hline $\begin{array}{l}\text { GRAPHDATABASE } \\
\text { represent and store data }\end{array}$ \\
\hline \hline $\begin{array}{l}\text { DOCUMENT- } \\
\text { ORIENTED } \\
\text { DATABASE }\end{array}$ & $\begin{array}{l}\text { A datructures for semantic queries with nodes, edges and properties to } \\
\text { information, also known as semi-structured data. Document-oriented databases are one of the main } \\
\text { categories of NoSQL databases. }\end{array}$ \\
\hline \hline $\begin{array}{l}\text { ESB (Enterprise } \\
\text { Service Bus) }\end{array}$ & $\begin{array}{l}\text { A "software architecture" model used for designing and implementing communication between mutually } \\
\text { interacting software applications in a service-oriented architecture (SOA). }\end{array}$ \\
\hline \hline Do you have any comments? \\
\hline
\end{tabular}

Thanks again for your time. Part 1 is complete.

Finally, you are going to answer Part 2: THE SMART DESTINATION APPROACH: ANALYSIS AND EVALUATION.

QUESTION 3. According to the concept and operational development of Smart Tourism Destinations as a new approach to destination management, please express your level of agreement or disagreement with the following statements on a scale from 1 (strongly disagree) to 5 (strongly agree).

Strongly disagree (1)-Partly disagree (2) -Neither agree nor disagree (3)- Agree (4)- Strongly agree (5)

\section{Statements}

It is too rhetorical and imprecise.

It is too ambitious and difficult to implement.

It is just a fad.

It is still experimental and requires the further maturation of emerging technologies.

Incorporates an added value to destination management and should be strengthened.

Has a fundamentally political-institutional nature

Is able to transform the management of tourist destinations.

Is linked to specific projects but lacks the capacity to transform a destination.

Is valid for the integration of ICTs in the management of destinations.

Is mainly developed as a specific business solution but not as a global process in destinations.

Will be always a subsidiary of a global smart city project.

Should result in an international standard (International Organization for Standardization, ISO).

Do you have any comments?

QUESTION 4. In the field of tourism management and the development of Smart Tourism Destinations, where do you think the application of these technologies/solutions would be most relevant? Please indicate your opinion on a scale from 1 (not relevant) to 5 (very relevant).

Not relevant (1)-Little relevance (2)- Relatively relevant (3)- Relevant (4)- Very relevant (5)

Areas for potential improvement

Governance improvement.

Greater sustainability. 
QUESTION 4. In the field of tourism management and the development of Smart Tourism Destinations, where do you think the application of these technologies/solutions would be most relevant? Please indicate your opinion on a scale from 1 (not relevant) to 5 (very relevant).

Increased innovation

Promotion of collective intelligence and knowledge at destination.

New possibilities for online marketing

Improvement in tourist information throughout the travel cycle (Inspiration-reservation-travel-stay-sharing experiences).

Better customization of the tourist-destination relationship.

Major tourist-resident interaction.

New distribution supply possibilities.

Increase in collaborative consumption.

Development of new business models.

Better information for destination management.

Travel experience enhancement.

Improvement in management of resources / tourist attractions.

Others: OPEN-ENDED RESPONSE

Do you have any comments?

QUESTION 5. In connection with the barriers to implementing ICTs in tourist destinations, please indicate your opinion on a scale from 1 (not important) to 5 (very important).

Not important (1)- Little importance (2)- Relatively important (3)- Important (4)- Very important (5)

Barriers for implementation

Lack of strategy for ICT application

Tourist organizations unadapted for this challenge

Lack of financial resources

Low absorption capacity of innovation in the tourism sector

Insufficient public-private cooperation

Restrictive legislation

Lack of connection between destination departments (Tourism; Culture; Land Planning, etc.)

Predominance of SMEs in the business structure

Lack of collaboration with universities and technology centres

Lack of ICT know-how

Lack of tourist engagement

Insufficient systems interoperability

Tourism management organizations lack competences over all areas related to the smart destination concept

Political short termism

Others: OPEN-ENDED RESPONSE

Do you have any comments?

QUESTION 6. With respect to the advantages of applying the Smart Tourism Destination approach and according the following topics, please express your level of agreement or disagreement on a scale from 1 (strongly disagree) to 5 (strongly agree).

Strongly disagree (1)- Disagree (2)- Neither agree nor disagree (3)- Agree (4)- Strongly agree (5)

Benefits derived

Increase in tourism demand.

Increase in tourism spending. 
QUESTION 6. With respect to the advantages of applying the Smart Tourism Destination approach and according the following topics, please express your level of agreement or disagreement on a scale from 1 (strongly disagree) to 5 (strongly agree).

Development of new tourism products.

Increase in the level of satisfaction of tourist demand

Increase in the competitiveness of the destination

New ways of financing tourism destinations

Improvement of public-private partnership

Others: OPEN-ENDED RESPONSE

Do you have any comments?

QUESTION 7. Finally, do you have any comments? 